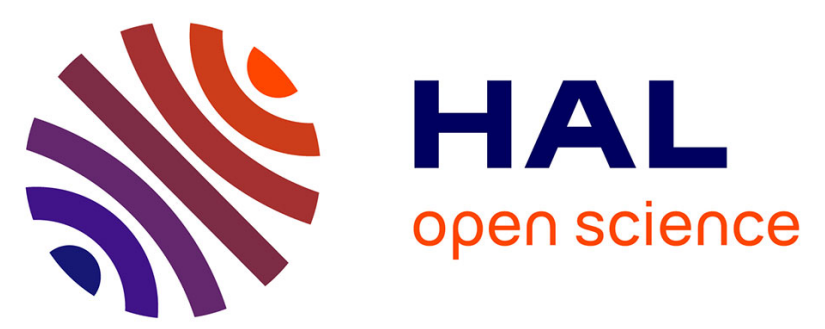

\title{
Importance of Combining Advanced Particle Size Analysis Techniques To Characterize Cell-Penetrating Peptide-Ferrocifen Self-Assemblies
}

Léna Guyon, Elise Lepeltier, Jean-Christophe Gimel, Brice Calvignac, Florence Franconi, Nolwenn Lautram, Aurélien Dupont, Claudie Bourgaux, Pascal Pigeon, Patrick Saulnier, et al.

\section{To cite this version:}

Léna Guyon, Elise Lepeltier, Jean-Christophe Gimel, Brice Calvignac, Florence Franconi, et al.. Importance of Combining Advanced Particle Size Analysis Techniques To Characterize Cell-Penetrating Peptide-Ferrocifen Self-Assemblies. Journal of Physical Chemistry Letters, 2019, 10 (21), pp.66136620. 10.1021/acs.jpclett.9b01493 . hal-02319158

\section{HAL Id: hal-02319158 \\ https: / hal.sorbonne-universite.fr/hal-02319158}

Submitted on 22 Oct 2019

HAL is a multi-disciplinary open access archive for the deposit and dissemination of scientific research documents, whether they are published or not. The documents may come from teaching and research institutions in France or abroad, or from public or private research centers.
L'archive ouverte pluridisciplinaire HAL, est destinée au dépôt et à la diffusion de documents scientifiques de niveau recherche, publiés ou non, émanant des établissements d'enseignement et de recherche français ou étrangers, des laboratoires publics ou privés. 


\section{The importance to combine advanced particle size}

\section{analysis techniques to characterize cell penetrating}

\section{peptide-ferrocifen self-assemblies}

Léna Guyon ${ }^{\dagger}$,Elise Lepeltier ${ }^{* \dagger}$, Jean-Christophe Gimel $^{\dagger}$, Brice Calvignac ${ }^{\dagger}$, Florence

Franconi $^{\dagger} \square$, Nolwenn Lautram ${ }^{\dagger}$, Aurélien Dupont ${ }^{\star}$, Claudie Bourgaux ${ }^{\S}$, Pascal Pigeon", Patrick

Saulnier $^{\dagger}$, Gérard Jaouen", Catherine Passirani ${ }^{\dagger}$

${ }^{\dagger}$ Micro et Nanomédecines Translationnelles, MINT, UNIV Angers, UMR INSERM 1066, UMR

CNRS 6021, Angers, France

PRISM Plate-forme de recherche en imagerie et spectroscopie multi-modales, PRISM-Icat, Angers et PRISM-Biosit CNRS UMS 3480, INSERM UMS 018, Rennes, UBL Universite Bretagne, Loire, France.

*Univ Rennes, CNRS, Inserm, BIOSIT - UMS 3480, US_S 018, F-35000 Rennes, France

${ }^{\S}$ Institut Galien Paris-Sud, UMR CNRS 8612, Faculté de Pharmacie, Université Paris-Sud XI, Châtenay-Malabry, France

"Sorbonne Université, UPMC Université Paris 06, UMR 8232, IPCM and PSL Chimie Paris Tech, Paris, France

*E-mail: elise.lepeltier@univ-angers.fr 
ABSTRACT: The design of simple platform in order to target the delivery of notably hydrophobic drugs into cancer cells is an ultimate goal. Here, three strategies were combined in a same nanovector, in limiting the use of excipients: a combination of cell-penetrating peptides (CPPs), amphiphilic prodrug and self-assembly. Light scattering and cryogenic transmission electron microscopy revealed one size population of object around $100 \mathrm{~nm}$ with a narrow size distribution. However, in-depth analysis of the suspension by nanoparticle tracking analysis (NTA), small angle X-ray scattering (SAXS) and NMR diffusometry demonstrated the presence of another population of small objects $(<2 \mathrm{~nm})$. It has been shown that these small selfassemblies represented more than $99 \%$ of the matter! This presence was clearly and unambiguously demonstrated by NMR diffusometry experiments. The study highlights the importance and the complementary contribution of each characterization methods in order to reflect the reality of the studied nanoassembly.

TOC GRAPHIC

KEYWORDS

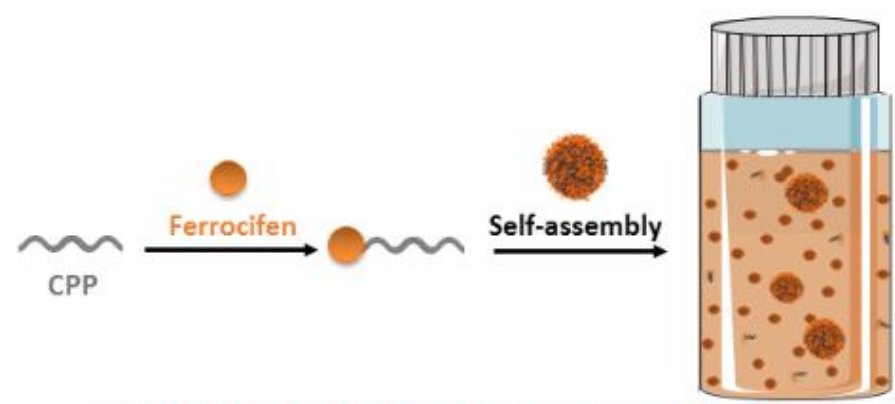

What are the best characterization methods?

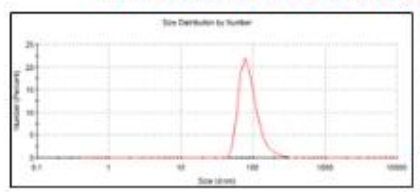

Dynamic Light Scattering

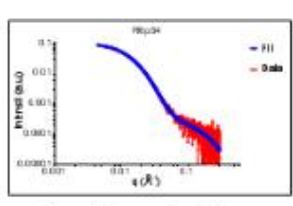

Small-angle X-ray scattering

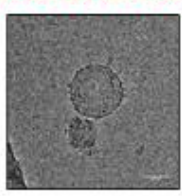

Cryo-TEM

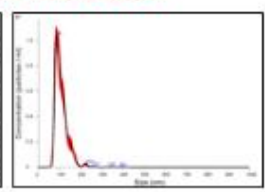

Nanoparticle

Tracking

Analysis

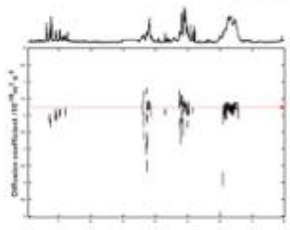

NMR diffusometry

Cell-penetrating 
peptide, ferrocifen, self-assemblies, light scattering, small angle X-ray scattering, NMR diffusometry

The use of nanocarrier-based drug delivery system presents several considerable advantages such as the specific targeting of a drug, its protection and its controlled release in order to improve the antitumor effect ${ }^{1}$. Moreover, this strategy would allow for an increase in drug loading with the controlled release in order to limit the burst phenomena ${ }^{2}$. The use of natural building blocks such as peptides has caught major attention for the fabrication of new materials $^{3-6}$. In fact, peptides have attractive properties due to their simple structure, biocompatibility by nature and a chemical diversity. Depending upon the amino acid sequence, the peptide can have various physicochemical properties such as the ability to interact with cell membranes ${ }^{7}$. These peptides, called cell-penetrating peptides (CPPs), were first dis-covered in 1988 from the HIV and gained much attention because of their ability to facilitate cellular uptake of a conjugated cargo ${ }^{8,9}$. These CPPs can be used to transport various hydrophobic anticancer drugs such as promising organometallic molecules: ferrocifen which combine hydroxytamoxifen and ferrocene together ${ }^{10,11}$. They present major properties as stability in non-oxidative environment, reversible oxidation-reduction (redox) potential, and impressive antiproliferative effects on various cancer cells ${ }^{12-14}$. The action mechanism of ferrocifens can be related to the oxidation state of iron in the ferrocene moiety. The oxidation of $\mathrm{Fe}^{2+}$ in $\mathrm{Fe}^{3+}$ by $\mathrm{O}_{2}$ leads to the generation of reactive radicals that could damage DNA strand. On the other side, the formation of reactive oxygen species causes the generation of selective electrophilic metabolites called quinone methides, that are responsible for biological alteration in cancer cell ${ }^{15-17}$.

In the present study, CPP-ferrocifen self-assemblies were designed and prepared for the efficient and targeted delivery of the drug into human lung cancer cells. For thus, a hydrophilic 
CPP was covalently linked with a hydrophobic ferrocifen (p54, chemical structure and synthesis scheme by saponification of its published ester ${ }^{18,19}$ were described in Figure S1 and section S1) in order to form an amphiphilic conjugate that could self-assemble into nanocarriers. RLW (RLWMRWYSPRTRAYG) was used as a specific CPP target human lung cancer cells (A549) ${ }^{20-}$ 22. Polyarginines containing between 6 and 9 arginine units $\left(\operatorname{Arg}_{n}, n=6-9\right)$, were used for comparison as CPP models ${ }^{23}$. In fact, these polycationic peptides have demonstrated to enter cells more effectively than other homopolymers, due to the guanidinium moiety ${ }^{24}$. The capacity of these conjugates to self-assemble was then evaluated by using a solvent displacement technique. The supramolecular organization of the nanostructures formed was fully characterized in order to correlate their physico-chemical properties with their biological effects and to predict their efficacy ${ }^{25,26}$. First by classical methods commonly used: dynamic light scattering (DLS) and cryogenic transmission electron microscopy (Cryo-TEM). Then by complementary and more complex technics: multiangle light scattering (MALS), nanoparticle tracking analysis (NTA), small angle X-ray scattering (SAXS) and nuclear magnetic resonance (NMR) diffusometry. The comparison of these methods was then achieved reflecting the importance of each experiment and underlying an important point: dynamic light scattering cannot be the only method used in order to reflect the size of self-assemblies. In fact, as it was mentioned in a previous study: several complementary methods should be used to provide reliable information needed for preclinical studies ${ }^{27}$.

Conjugates were successfully synthesized using standard solid phase peptide synthesis protocol (SPPS) with a Fmoc strategy on rink amide resin ${ }^{28}$. An automated microwave peptide synthesizer was used to reduce synthesis time and increase the crude peptide purity ${ }^{29}$. The identification of the products was achieved by mass spectrometry (LC-MS/MS) and NMR 
experiments (sections S1, S2, Figure S2 and Table S1 in Supporting Information). CPP-p54 were obtained with a yield of around $22 \%$ and a purity ranging from $88 \%$ to $98 \%$ (Table S1 in Supporting Information). The properties of CPP-p54 to self-assemble was investigated by the pyrene fluorescence 1:3 ratio method (Supporting Information, Table S1) ${ }^{30}$. To ensure the assembly, the critical aggregation concentration (CAC) of each conjugate was determined. For thus, the ratio of pyrene vibronic band intensities $\left(\mathrm{I}_{372} / \mathrm{I}_{382}\right)$ was plotted and fitted by a Boltzmann-type sigmoid (for more detailed information, see section S3 and Figure S3 in Supporting Information $)^{28-30}$. The CAC of each system was determined as the first sharp decrease point (Figure 1) ${ }^{6}$. The conjugate concentrations corresponding to the CAC values are listed in Table 1.

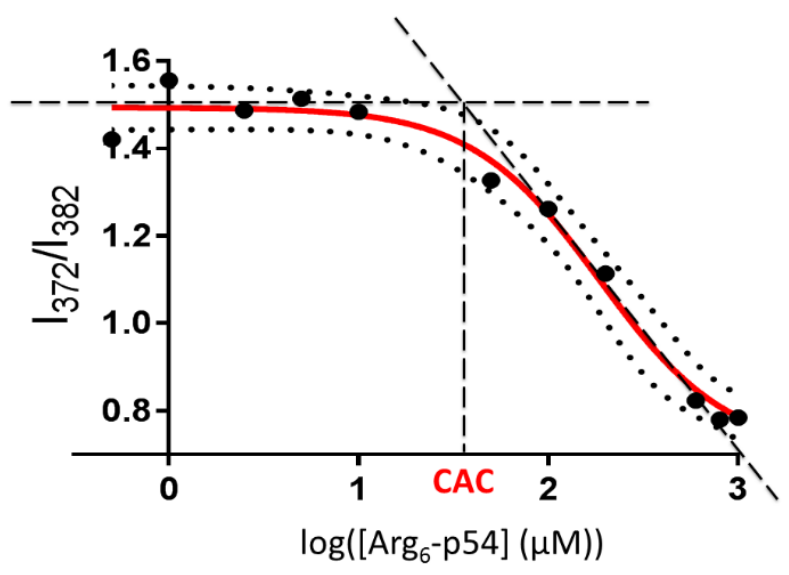

Figure 1. Boltzmann-type sigmoid obtained for $\mathrm{Arg}_{6}$-p54 suspension in water showing the CAC value, corresponding to the first sharp decrease point.

Table 1. CAC measurements of the different conjugates used and ferrocifen alone. The concentration was determined using pyrene as fluorescent dye.

\begin{tabular}{|c|c|c|}
\hline Compound & CAC $(\mu \mathrm{g} / \mathrm{mL})$ & CAC $(\mu \mathrm{M})$ \\
\hline $\operatorname{Arg}_{6}$-p54 & 52 & 37 \\
\hline $\operatorname{Arg}_{7}$-p54 & 75 & 48 \\
\hline $\operatorname{Arg}_{8}$-p54 & 170 & 99 \\
\hline $\operatorname{Arg}_{9}$-p54 & 210 & 113 \\
\hline $\mathrm{RLW}-\mathrm{p} 54$ & 771 & 314 \\
\hline
\end{tabular}


The fluorescence method showed not solely the influence of the concentration on the selfassembly but also the impact of each part (peptide and ferrocifen) on the nanostructure formation. According to results obtained in Table 1, the peptide length has an impact on the CAC value: an increase of the $\mathrm{CAC}$ was observed when the peptide length increased. Moreover, this experiment was also performed with peptide alone and ferrocifen as controls. For peptide alone, the fluorescence intensity was constant, whatever the concentration used, indicating by this technique that no assembly structures were observed (Figure S4 in Supporting Information). Interestingly, data obtained for ferrocifen alone are well fitted by a Boltzmann-type sigmoid showing the onset of self-assembly at $325 \mu \mathrm{g} / \mathrm{mL}$. However, a precipitate was clearly observed and the fluorescence measurement was obviously only performed on the part in suspension. This very low stability with ferrocifen alone showed the important role of the peptide moiety. In fact, conjugates suspensions have shown to be stable at least one month at $4^{\circ} \mathrm{C}$ (Figure $\mathrm{S} 5$ in the Supporting Information). According to this, peptides would bring stability to self-assemblies thanks to potential hydrogen bonds between amino acid sequences ${ }^{31,32}$. Additionally, the ferrocifen would drive the self-assembly mechanism, via notably a $\pi-\pi$ stacking from ferrocene moiety $^{6,33,34}$.

Self-assemblies were formulated by nanoprecipitation method. In this microfluidic formulation process, conjugates are used alone, without adding any other excipients in order to have a theoretical drug loading of around $30 \%$ in mol. This strategy allows to reach a high drug loading 
compared to conventional nanocarriers such as liposomes ${ }^{35}$. The purified conjugates were solubilized in acetone $(3 \mathrm{mg} / \mathrm{mL})$ and this organic solution was added to water via a microfluidic mixer. The organic solvent was then removed using a rotary evaporator and the final concentrations obtained were close to $1 \mathrm{mg} / \mathrm{mL}$ for all the different suspensions, above the CAC values (see Table 1 and Section S4 in Supporting Information).

First step of the self-assembly characterization was performed on a classical and daily used DLS Zetasizer® Nano ZS (Malvern Instruments S.A., UK) with a $4 \mathrm{~mW}, 633 \mathrm{~nm}$ laser and a scattering angle at $173^{\circ}$. The hydrodynamic diameter and the particle size polydispersity index (PDI) of each suspension were determined using the cumulant analysis ${ }^{36}$. Interestingly, CPP-p54 suspensions showed nanostructures in size ranging from 111 to $128 \mathrm{~nm}$ depending on the conjugate used in the formulation process (Table 2). Moreover, PDI obtained were smaller than 0.25 , indicating a limited polydispersity. The high zeta potential $(+30 \mathrm{mV})$ of self-assemblies was related to positively charged guanidino groups, creating repulsion between particles and improvement of the suspension stability. Moreover, this high zeta potential could increase cellular internalization by facilitating a charge-based interaction with negatively charged cell membrane surface ${ }^{37}$. Due to the fact that the signal intensity obtained by DLS was very low for each measurement (not enough scattered photons), MALS was also used to have complementary information. This method is based on the measurement of the scattering intensity as a function of the scattering angles. Measurements were performed on a LS Spectrometer with a $500 \mathrm{~mW}, 660$ $\mathrm{nm}$ laser using 20 angles ranging from $20^{\circ}$ to $150^{\circ}$ (LS Instruments AG, Switzerland). Results were analyzed using the Guinier relationship ${ }^{38}$ (Table 2). The evolution of the average relaxation rate $(\Gamma)$ as a function of the square scattering vector $\left(\mathrm{q}^{2}\right)$ has been provided in Supporting Information (Figure S6) for $\mathrm{Arg}_{6}$-p54 after a $0.2 \mu \mathrm{m}$ filtration. A linear dependence is clearly 
evidenced demonstrating the Brownian behavior of the scatterers. Moreover, MALS was also performed after filtration on $0.02 \mu \mathrm{m}$ pore size membrane but the scattered intensity of the selfassemblies was too close to the one of the solvent to measure a correlogram. The intercept of $\mathrm{g}_{2}(\mathrm{t})$ falls to 0.4 after a $0.1 \mu \mathrm{m}$ filtration and an inverse Laplace transform (ILT) was performed on correlograms at $150^{\circ}$ (Figure 2 and Supplementary Section S5). Inverse Laplace Transform (ILT) on DLS signals were performed using a constrained regularization calculation algorithm called REPES ${ }^{39}$. ILT is mathematically ill-conditioned and very sensitive to noise in the data especially in the case of multimodal relaxation processes ${ }^{40}$. A $3 \%$ fast contribution in intensity arises but it was not enough to give a reliable size measurement (around $1 \mathrm{~nm}$ ).
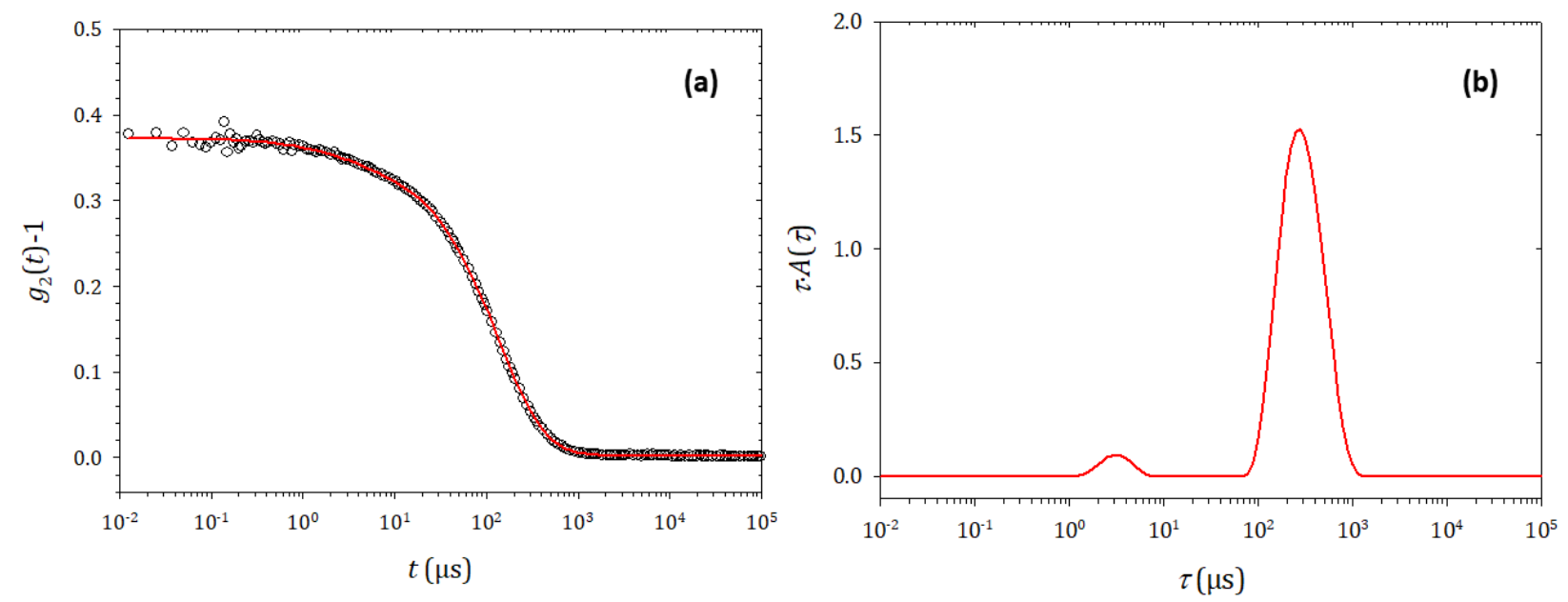

Figure 2. MALS analysis of $\operatorname{Arg}_{6}-\mathrm{p} 54$ suspension after filtration though $0.1 \mu \mathrm{m}$. (a) Autocorrelation function of the scattering intensity at $\theta=150^{\circ}$ for a filtered $\operatorname{Arg}_{6}-\mathrm{p} 54$ solution in water $20^{\circ} \mathrm{C}$. The red line corresponds to the fit of the experimental points using the REPES ILT algorithm and (b) corresponding relaxation time distribution obtained from an ILT of the autocorrelation function displayed in figure 2 a, using the REPES algorithm. The contribution of the fast mode is around $4 \%$ and the hydrodynamic diameter is of the order of $1 \mathrm{~nm}$ while the slow mode (96\%) gives an average hydrodynamic diameter close to $65 \mathrm{~nm}$.

Cryo-TEM analysis were performed to observe the objects in their native form (for more detailed information, see section S6 in the Supporting Information). Consistent with the results obtained by light scattering, Cryo-TEM images of the self-assemblies showed the predominance 
of particles with a size of $79 \pm 30 \mathrm{~nm}$ and a slight polydispersity. Furthermore, spherical morphology of self-assemblies was observed with some dense electron objects at the surface of nanostructures for Arg 8 -p54 and Arg 9 -p54 (Figure 3). These objects could be polyarginine fibrils or aggregates. In fact, it was demonstrated that $\operatorname{Arg}_{9}$ was partly unstructured in pure water but

(A)
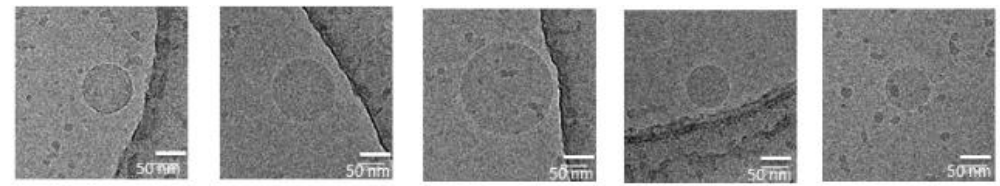

(B)
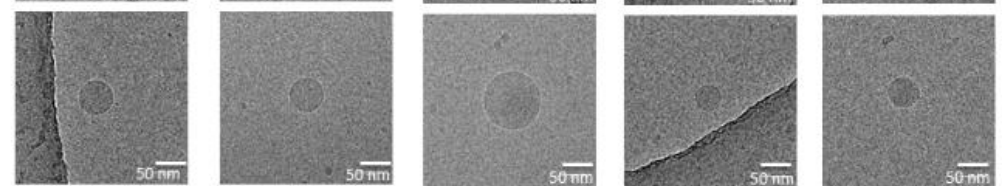

(C)
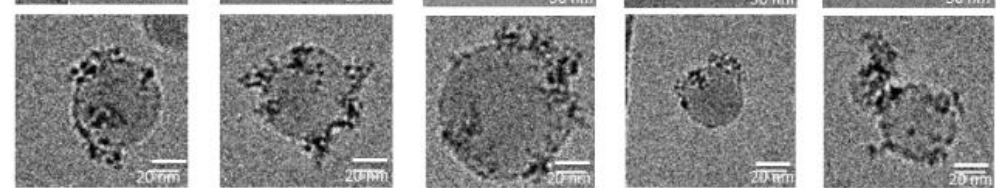

(D)
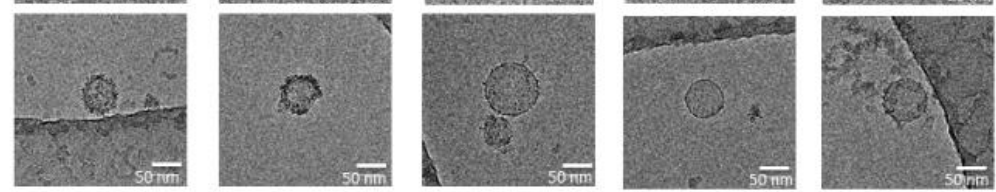

(E)
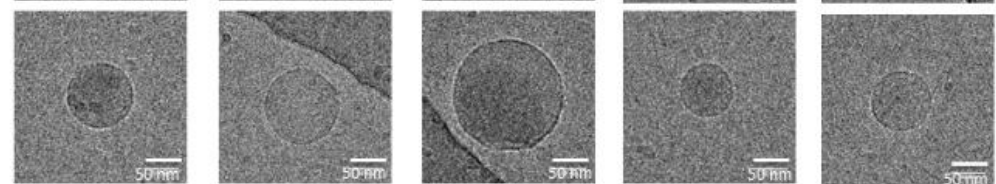

Figure 3. Cryo-TEM images of self-assemblies formed with different conjugates: $\operatorname{Arg}_{6}-\mathrm{p} 54$ (A), $\operatorname{Arg}_{7}$-p54 (B), Arg 8 -p54 (C), Arg 9 -p54 (D) and RLW-p54 (E) at a concentration of $10 \mathrm{mg} / \mathrm{mL}$ (post-formulation concentration).

could be present in a random coil structure ${ }^{41}$. Short polyarginines could remain unstructured when they have less than 8 arginine units. Interestingly, spherical morphology for all CPP-p54 self-assemblies were obtained ( $\operatorname{Arg}_{\mathrm{n}}$-p54 and RLW-p54) despite the difference in primary structure and in peptide length. Moreover, no significant modification of size was observed between each conjugate. However, in carefully looking Figure 3 A, really small spherical objects were observed: these small particles could be artefacts or micelles. 
NTA measurements were also performed (see section S7 and Figure S7 in the Supporting Information). This method allows to determine not solely the number size distribution but also the concentration of nanoparticle population ${ }^{42}$. However, it is important to note that this technique does not detect all particles. In fact, particles that are not scattering in the laser beam, either because they are too small or because their refractive index is very close to water, are not detected. Thanks to these measurements, and assuming spherical homogeneous objects with a density close to $1 \mathrm{~g} / \mathrm{mL}$, the nanoparticle volume and mass concentrations were evaluated in order to estimate the amount of matter involved in the nanoparticles observed (Table 2).

Table 2. Features of CPP-p54 self-assemblies after filtration through $0.2 \mu \mathrm{m}$ obtained by DLS, MALS and NTA. $D_{\mathrm{h}}$ is the hydrodynamic diameter, $D_{\mathrm{g}}$ is the diameter of gyration and PDI the particle size polydispersity index. Volume of particle and percentage of matter forming selfassemblies are calculated from the features obtained by NTA, assuming that homogeneous spheres with an electron density of 1 were obtained. PDI obtained by NTA were calculated according to the following equation: $(\mathrm{SD} / \mathrm{mean})^{2}$. Measurements are expressed as the average \pm SD.

\begin{tabular}{|c|c|c|c|c|c|c|c|c|c|c|}
\hline & \multicolumn{3}{|c|}{ DLS } & \multicolumn{3}{|c|}{ MALS } & \multicolumn{4}{|c|}{ NTA } \\
\hline Conjugate & $\begin{array}{c}D_{\mathrm{h}} \\
(\mathrm{nm})\end{array}$ & PDI & $\begin{array}{c}\text { Zeta } \\
\text { potential } \\
(\mathrm{mV})\end{array}$ & $\begin{array}{c}D_{\mathrm{h}} \\
(\mathrm{nm})\end{array}$ & $\begin{array}{c}D_{\mathrm{g}} \\
(\mathrm{nm})\end{array}$ & PDI & $\begin{array}{c}D_{\mathrm{h}} \\
(\mathrm{nm})\end{array}$ & PDI & $\begin{array}{l}\text { Concentration } \\
\text { (particles } / \mathrm{mL} \text { ) }\end{array}$ & $\begin{array}{c}\text { Percentage } \\
\text { of matter } \\
\text { forming } \\
\text { visible self- } \\
\text { assemblies } \\
\text { (\%) }\end{array}$ \\
\hline $\operatorname{Arg}_{6}-\mathrm{p} 54$ & $\begin{array}{c}128 \pm \\
26\end{array}$ & $\begin{array}{c}0.16 \pm \\
0.03\end{array}$ & $23 \pm 2$ & $\begin{array}{r}75.9 \\
\pm 0.6\end{array}$ & $\begin{array}{l}62.2 \\
\pm 0.6\end{array}$ & $\begin{array}{c}0.08 \pm \\
0.02\end{array}$ & $\begin{array}{c}59.2 \pm \\
1.6\end{array}$ & $\begin{array}{c}0.05 \pm \\
0.01\end{array}$ & $\begin{array}{c}5 \times 10^{10} \pm 7 \times \\
10^{9}\end{array}$ & $0.6 \pm 0.1$ \\
\hline $\operatorname{Arg}_{7-p} 54$ & $\begin{array}{c}114 \pm \\
15\end{array}$ & $\begin{array}{l}0.19 \pm \\
0.02\end{array}$ & $19 \pm 6$ & $\begin{array}{r}79.1 \\
\pm 0.6\end{array}$ & $\begin{array}{r}66.0 \\
\pm 0.5\end{array}$ & $\begin{array}{c}0.11 \pm \\
0.1\end{array}$ & $\begin{array}{c}91.0 \pm \\
7\end{array}$ & $\begin{array}{c}0.10 \pm \\
0.01\end{array}$ & $9 \times 10^{9} \pm 8 \times 10^{8}$ & $0.5 \pm 0.1$ \\
\hline $\operatorname{Arg}_{8}-\mathrm{p} 54$ & $\begin{array}{c}117 \pm \\
24\end{array}$ & $\begin{array}{c}0.18 \pm \\
0.02\end{array}$ & $35 \pm 2$ & $\begin{array}{l}59.4 \\
\pm 0.4\end{array}$ & $\begin{array}{l}51.2 \\
\pm 0.6\end{array}$ & $\begin{array}{c}0.14 \pm \\
0.1\end{array}$ & $\begin{array}{c}78.0 \pm \\
1\end{array}$ & $\begin{array}{c}0.06 \pm \\
0.01\end{array}$ & $\begin{array}{c}3 \times 10^{10} \pm 2 \times \\
10^{9}\end{array}$ & $1.0 \pm 0.1$ \\
\hline $\operatorname{Arg}_{9-\mathrm{p}} 54$ & $\begin{array}{c}111 \pm \\
17\end{array}$ & $\begin{array}{c}0.15 \pm \\
0.04\end{array}$ & $32 \pm 3$ & $\begin{array}{r}78.7 \\
\pm 0.7 \\
\end{array}$ & $\begin{array}{l}57.6 \\
\pm 0.6 \\
\end{array}$ & $\begin{array}{c}0.14 \pm \\
0.2\end{array}$ & $\begin{array}{c}71.0 \pm \\
1\end{array}$ & $\begin{array}{c}0.03 \pm \\
0.00\end{array}$ & $6 \times 10^{9} \pm 8 \times 10^{8}$ & $0.1 \pm 0.1$ \\
\hline RLW-p54 & $\begin{array}{c}122 \pm \\
6\end{array}$ & $\begin{array}{c}0.19 \pm \\
0.04\end{array}$ & $41 \pm 1$ & $\begin{array}{r}63.9 \\
\pm 0.7 \\
\end{array}$ & $\begin{array}{l}58.8 \\
\pm 0.4 \\
\end{array}$ & $\begin{array}{c}0.21 \pm \\
0.2\end{array}$ & $\begin{array}{c}77.0 \pm \\
2\end{array}$ & $\begin{array}{c}0.06 \pm \\
0.01\end{array}$ & $6 \times 10^{9} \pm 1 \times 10^{9}$ & $0.2 \pm 0.1$ \\
\hline
\end{tabular}


According to these measurements, the nanoparticle population observed represents only less than $1 \%$ of the initial matter in solution. To understand this loss of material, a basic but powerful quantification by successive filtrations was performed through $0.2 \mu \mathrm{m}, 0.1 \mu \mathrm{m}$ and $0.02 \mu \mathrm{m}$ filter pore sizes (Whatman ${ }^{\mathrm{TM}}$ Anotop $^{\mathrm{TM}}$ syringe filter). Suspension was analyzed more deeply for Arg $_{6}$-p54 using light scattering (NTA and MALS) after each filtration and freeze-dried. However, after a filtration on $0.02 \mu \mathrm{m}$, the scattered intensity became very weak and it was impossible to measure a correlation function in DLS. After a filtration on $0.1 \mu \mathrm{m}$, the size decreases $(53 \pm 1 \mathrm{~nm})$, the PDI values increases $(0.40 \pm 0.01)$ and the intercept of the correlation function drops to 0.37. Size and PDI values were obtained using a cumulant analysis (which calculates averages in the frequency domain) and the small fast contribution obtained by ILT (see figure 2) can explain the increase of the polydispersity. This weak fast contribution makes the determination of the corresponding size unreliable. As said previously, it corresponds to particles around $1 \mathrm{~nm}$ diameter. This step proved again the DLS limitations with a low scattering material. Results obtained were unmistakable: around $100 \%$ of conjugate was still present in the suspension after filtration through $0.02 \mu \mathrm{m}$ (same amount of conjugate compared to initial suspension without filtration). These results were in agreement with NTA measurements: visible self-assemblies represent an insignificant fraction of the conjugate mass (Table 3).

Table 3. Features of $\operatorname{Arg}_{6}$-p54 self-assemblies obtained without filtration, after filtration through $0.20 \mu \mathrm{m}, 0.10 \mu \mathrm{m}$ and $0.02 \mu \mathrm{m}$. Characteristics were obtained by NTA, MALS and after freezedrying. $D_{\mathrm{h}}$ is the hydrodynamic diameter and PDI the particle size polydispersity index. The percentage of matter forming visible self-assemblies are calculated assuming that homogeneous spheres with an electron density of 1 were obtained. Measurements are expressed as the average \pm SD. ND: Not Determined.

\begin{tabular}{|l|l|l|l|}
\hline Arg $_{6}$-p54 & MALS & NTA & Freeze-drying \\
\hline
\end{tabular}




\begin{tabular}{|l|l|l|l|l|l|l|}
\hline & $D_{\mathrm{h}}(\mathrm{nm})$ & PDI & $D_{\mathrm{h}}(\mathrm{nm})$ & $\begin{array}{l}\text { Percentage of } \\
\text { Concentration } \\
\text { particles } / \mathrm{mL})\end{array}$ & $\begin{array}{l}\text { matter forming } \\
\text { visible } \\
\text { assemblies (\%) }\end{array}$ & $\begin{array}{l}\text { Concentration } \\
(\mathrm{mg} / \mathrm{mL})\end{array}$ \\
\hline $\begin{array}{l}\text { Without } \\
\text { filtration }\end{array}$ & ND & ND & $98 \pm 3$ & $6 \times 10^{9} \pm 3 \times 10^{8}$ & 0.4 & $0.65 \pm 0.16$ \\
\hline $0.2 \mu \mathrm{m}$ & $83 \pm 1$ & $\begin{array}{l}0.08 \\
0.01\end{array}$ & $84 \pm 1$ & $5 \times 10^{9} \pm 8 \times 10^{8}$ & 0.2 & $0.64 \pm 0.15$ \\
\hline $0.1 \mu \mathrm{m}$ & $53 \pm 1$ & $\begin{array}{l}0.40 \\
0.01\end{array}$ & $56 \pm 1$ & $2 \times 10^{9} \pm 1 \times 10^{8}$ & 0.02 & $0.63 \pm 0.15$ \\
\hline $0.02 \mu \mathrm{m}$ & ND & ND & ND & ND & ND & $0.67 \pm 0.16$ \\
\hline
\end{tabular}

In addition to these analysis, SAXS experiments were conducted on the SWING beamline at the SOLEIL synchrotron (Saint Aubin, France). Data were collected as a function of the scattering vector (see section S8 and Figure S8 in Supporting Information). Water scattering was subtracted from sample patterns. Curves were fitted with log-normal distributions of homogeneous spheres all with the same electron density. A bimodal size distribution had to be used for $\operatorname{Arg}_{6}$-p54, $\operatorname{Arg}_{7}-\mathrm{p} 54, \operatorname{Arg}_{8}$-p54, $\operatorname{Arg}_{9}$-p54 to take into account the scattering intensity at high q. From figure 4, we clearly see that small objects contribute to the scattered intensity only for $\mathrm{q}$ above $0.005 \AA^{-1}$. At low q, the scattered intensity is dominated by aggregates. 


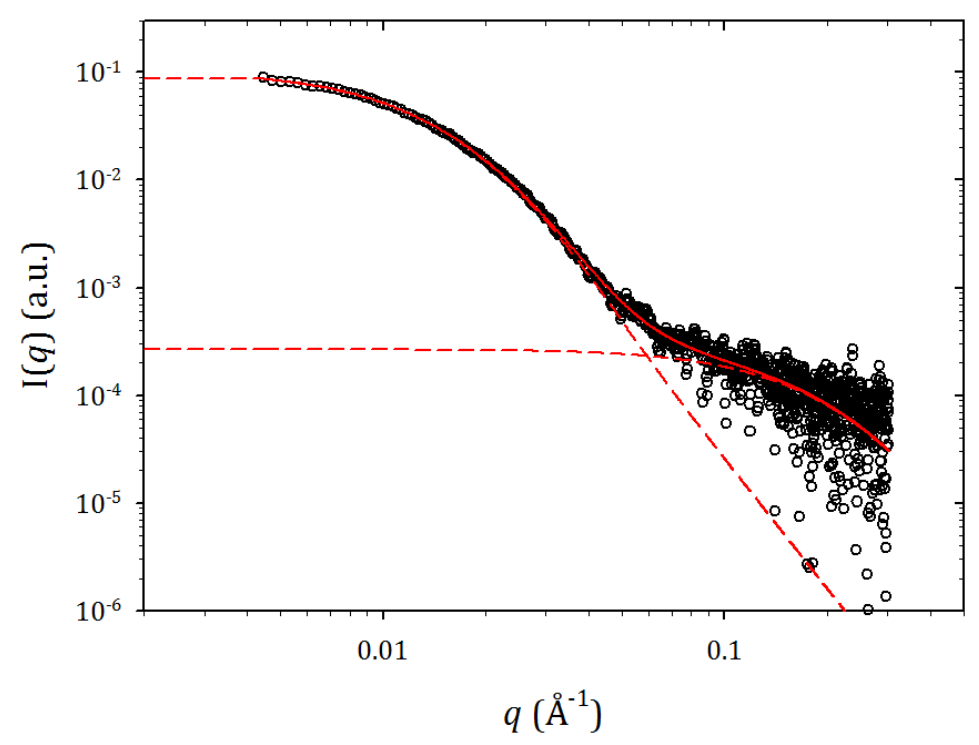

Figure 4. Small-angle X-ray scattering pattern recorded at room temperature and fitted curve obtained for $\mathrm{Arg}_{6}$-p54. Open circles are experimental data and the full red line represents the fit to the data using two log-normal distributions of spheres. Red dotted lines represent individual contributions of both distributions.

Figure 5 gives an example of distribution curves obtained for $\operatorname{Arg}_{6}$-p54. The intensity distribution gives a strong contribution to big self-assemblies, compared to the number distribution that gives a strong contribution to small objects (see Table S2 in Supporting Information $)^{43}$. According to these measurements, two populations of spherical objects were observed for $\operatorname{Arg}_{\mathrm{n}}-\mathrm{p} 54$ : one population with a radius lower than $2 \mathrm{~nm}$ and another population with a radius around $20-25 \mathrm{~nm}$. These results are in agreement with NTA analysis and the quantification after filtration: the conjugate self-assembled mainly into nanoobjects smaller than $5 \mathrm{~nm}$ (mass fraction higher than 0.99). 


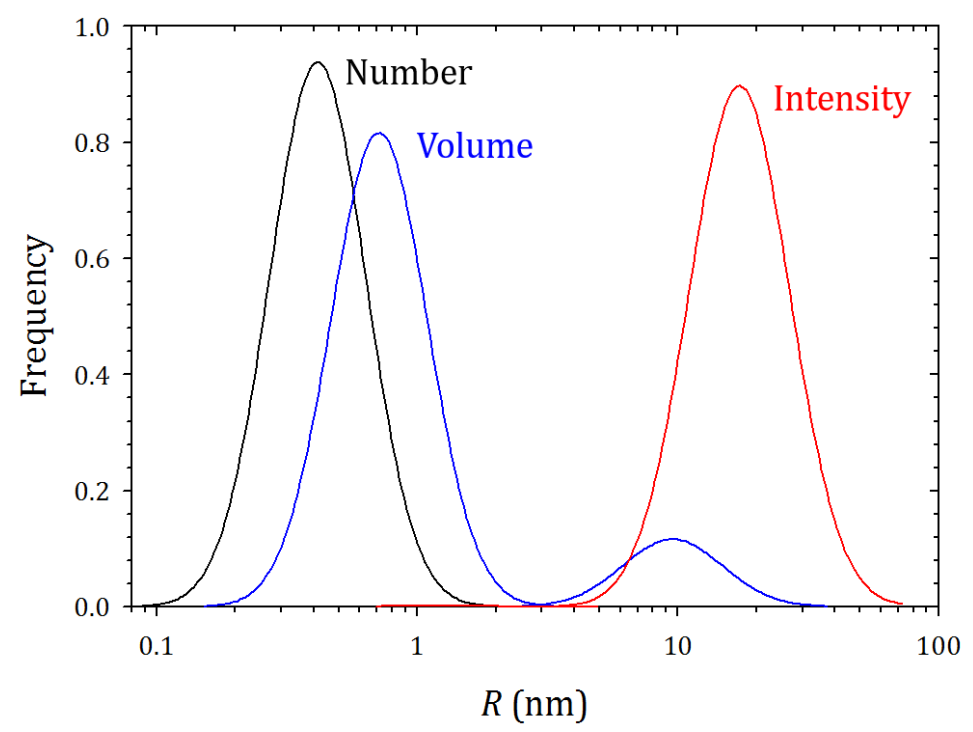

Figure 5. Distribution curves obtained for $\operatorname{Arg}_{6}$-p54 by SAXS measurements: number distribution (black curve), volume distribution (blue curve) and intensity distribution (red curve $)^{43}$. The area bellow curves has been normalized to unity.

Finally, $\operatorname{Arg}_{6}$-p54 self-assembly suspension was investigated using NMR diffusometry ${ }^{44}$ (see section S9 in Supplementary Information): smaller self-assemblies should diffuse faster compared to larger nanostructures and should give the major contribution in term of protons. DOSY results in $\mathrm{D}_{2} \mathrm{O}$ (Figure 6) reveal particles with a hydrodynamic diameter close to $2.3 \mathrm{~nm}$ while in deuterated acetone (where both $\operatorname{Arg}_{6}$ and p54 are soluble) they have only $1.6 \mathrm{~nm}$ hydrodynamic diameter (see Figure S9 in Supporting Information). Therefore, the self-assembled structures (demonstrated by the pyrene fluorescence measurements) should have a low aggregation number. 

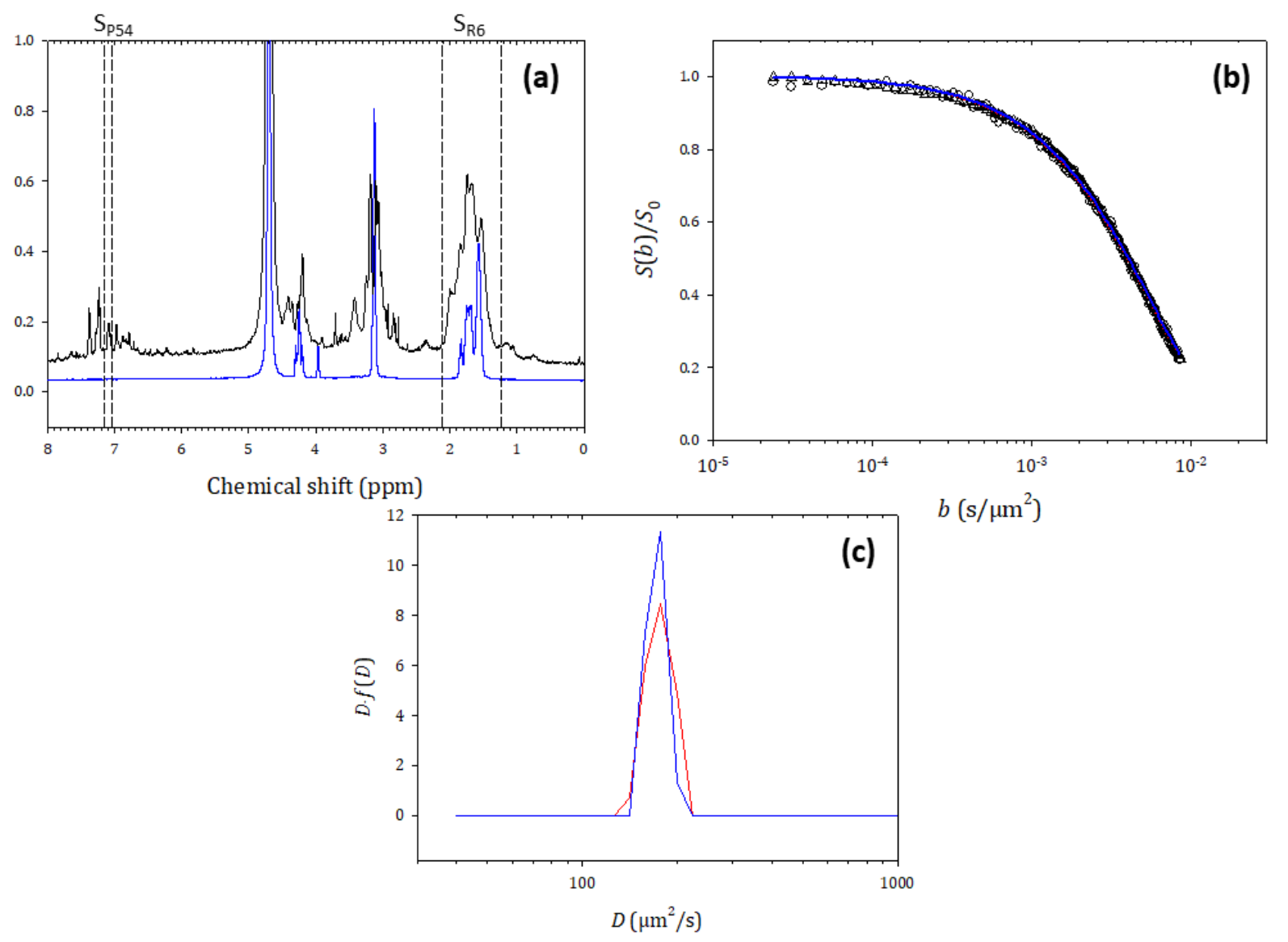

Figure 6. Results obtained by NMR diffusometry in $\mathrm{D}_{2} \mathrm{O}$ : (a) ${ }^{1} \mathrm{H}$ NMR spectra in $\mathrm{D}_{2} \mathrm{O}$ of $\operatorname{Arg}_{6}$ (blue curve) and $\mathrm{Arg}_{6}$-p54 (black curve). Dashed lines display integration domains used to characterize proton signals from p54 $\left(\mathrm{S}_{\mathrm{P} 54}: 7.155\right.$ - $\left.7.033 \mathrm{ppm}\right)$ and $\operatorname{Arg}_{6}\left(\mathrm{~S}_{\mathrm{R} 6}: 2.111\right.$ - 1.237 ppm) ; (b) PFG-NMR experiments in $\mathrm{D}_{2} \mathrm{O}$ at $25^{\circ} \mathrm{C}$. Attenuation of integrated NMR signals as a function of the diffusion weighted factor, b, for p54 (circles) and $\mathrm{Arg}_{6}$ (triangles). Lines correspond to the fit of the experimental points, p54 (red) and $\operatorname{Arg}_{6}$ (blue) using the REPES ILT algorithm. (c) Corresponding diffusion coefficient distributions obtained from the ILT of signals displayed in figure $6 \mathrm{~b}$, p54 (red) and Arg $_{6}-\mathrm{p} 54$ (blue). Average diffusion coefficients are 172 $\mu^{2} / \mathrm{s}$ (blue) and $176 \mu \mathrm{m}^{2} / \mathrm{s}$ (red). Both correspond to objects with a hydrodynamic diameter close to $2.3 \mathrm{~nm}$.

In summary, an innovative platform was set up to transport a hydrophobic anticancer drug. The synthesis of amphiphilic conjugates (CPP-p54) formed by two different types of cellpenetrating peptides $\operatorname{Arg}_{\mathrm{n}}-\mathrm{p} 54(\mathrm{n}=6$ to 9$)$ and RLW-p54, their self-assembly in water as well as the complete characterization of the objects formed were studied. This study highlights the 
importance of the method used to characterize the suspension. Based on recent analysis, dynamic light scattering has been the most common method used to characterize the size of nanoparticles enabled medicinal products (NEP) thanks to that its fast and inexpensive analysis. In fact, this technique and microscopy were used in respectively $48 \%$ and $14 \%$ of reporting applications: only $8 \%$ of NEP were characterized by other complementary methods ${ }^{45}$. In this project, dynamic light scattering is not adapted to characterize self-assemblies. Indeed, it is important to note that this method gives strong contribution to big objects even if these objects represent less than $1 \%$ of the initial matter used. According to this, DLS, known to be a low-resolution technique, must be used only for an initial analysis ${ }^{46-49}$ : it is essential to perform complementary methods such as SAXS, quantification after filtration or NMR diffusometry to obtain a reliable characterization, unlike what is traditionally done in the nanomedicine field.

\section{ASSOCIATED CONTENT}

Supporting Information: materials, synthesis, purification, CAC determination, stability, characterization methods.

\section{ACKNOWLEDGMENT}

This work benefited from the support of a CIFRE project ( $n^{\circ}$ 2016/68) managed by ANRT (Association Nationale Recherche Technologique). We acknowledge SOLEIL for provision of synchrotron radiation facilities and we would like to thank Javier Perez for assistance using the beamline SWING (Proposal ID: 20170722). We would like also to acknowledge Benjamin Siegler (ASTRAL-SFR Matrix, Angers) for his technical support. 


\section{REFERENCES}

(1) Hossen, S.; Hossain, M. K.; Basher, M. K.; Mia, M. N. H.; Rahman, M. T.; Uddin, M. J. Smart Nanocarrier-Based Drug Delivery Systems for Cancer Therapy and Toxicity Studies: A Review. Journal of Advanced Research 2018. https://doi.org/10.1016/j.jare.2018.06.005.

(2) Huang, X.; Brazel, C. S. On the Importance and Mechanisms of Burst Release in MatrixControlled Drug Delivery Systems. Journal of Controlled Release 2001, 73 (2-3), 121136. https://doi.org/10.1016/S0168-3659(01)00248-6.

(3) Guyon, L.; Lepeltier, E.; Passirani, C. Self-Assembly of Peptide-Based Nanostructures: Synthesis and Biological Activity. Nano Res. 2018, 11 (5), 2315-2335. https://doi.org/10.1007/s12274-017-1892-9.

(4) Edwards-Gayle, C. J. C.; Hamley, I. W. Self-Assembly of Bioactive Peptides, Peptide Conjugates, and Peptide Mimetic Materials. Org. Biomol. Chem. 2017, 15 (28), 58675876. https://doi.org/10.1039/c7ob01092c.

(5) Wang, Y.; Cheetham, A. G.; Angacian, G.; Su, H.; Xie, L.; Cui, H. Peptide-Drug Conjugates as Effective Prodrug Strategies for Targeted Delivery. Adv. Drug Deliv. Rev. 2017, 110-111, 112-126. https://doi.org/10.1016/j.addr.2016.06.015.

(6) Fan, Q.; Ji, Y.; Wang, J.; Wu, L.; Li, W.; Chen, R.; Chen, Z. Self-Assembly Behaviours of Peptide-Drug Conjugates: Influence of Multiple Factors on Aggregate Morphology and Potential Self-Assembly Mechanism. $R$ Soc Open Sci 2018, 5 (4), 172040. https://doi.org/10.1098/rsos.172040.

(7) Bechara, C.; Sagan, S. Cell-Penetrating Peptides: 20 Years Later, Where Do We Stand? FEBS Lett. 2013, 587 (12), 1693-1702. https://doi.org/10.1016/j.febslet.2013.04.031.

(8) Frankel, A. D.; Pabo, C. O. Cellular Uptake of the Tat Protein from Human Immunodeficiency Virus. Cell 1988, 55 (6), 1189-1193.

(9) Green, M.; Loewenstein, P. M. Autonomous Functional Domains of Chemically Synthesized Human Immunodeficiency Virus Tat Trans-Activator Protein. Cell 1988, 55 (6), 1179-1188. https://doi.org/10.1016/0092-8674(88)90262-0.

(10) Braga, S. S.; Silva, A. M. S. A New Age for Iron: Antitumoral Ferrocenes. Organometallics 2013, 32 (20), 5626-5639. https://doi.org/10.1021/om400446y.

(11) Jaouen, G.; Vessières, A.; Top, S. Ferrocifen Type Anti Cancer Drugs. Chem Soc Rev 2015, 44 (24), 8802-8817. https://doi.org/10.1039/c5cs00486a.

(12) Jaouen, G.; Top, S. The Ferrocifen Family as Potent and Selective Antitumor Compounds: Mechanisms of Action. In Advances in Organometallic Chemistry and Catalysis; WileyBlackwell, 2013; pp 563-580. https://doi.org/10.1002/9781118742952.ch42.

(13) Wang, Y.; Heinemann, F.; Top, S.; Dazzi, A.; Policar, C.; Henry, L.; Lambert, F.; Jaouen, G.; Salmain, M.; Vessieres, A. Ferrocifens Labelled with an Infrared Rhenium Tricarbonyl Tag: Synthesis, Antiproliferative Activity, Quantification and Nano IR Mapping in Cancer Cells. Dalton Trans. 2018, 47 (29), 9824-9833. https://doi.org/10.1039/C8DT01582A.

(14) Singh, A.; Lumb, I.; Mehra, V.; Kumar, V. Ferrocene-Appended Pharmacophores: An Exciting Approach for Modulating the Biological Potential of Organic Scaffolds. Dalton Trans. 2019, 48 (9), 2840-2860. https://doi.org/10.1039/C8DT03440K. 
(15) Osella, D.; Ferrali, M.; Zanello, P.; Laschi, F.; Fontani, M.; Nervi, C.; Cavigiolio, G. On the Mechanism of the Antitumor Activity of Ferrocenium Derivatives. Inorganica Chimica Acta 2000, 306 (1), 42-48. https://doi.org/10.1016/S0020-1693(00)00147-X.

(16) Hillard, E.; Vessières, A.; Thouin, L.; Jaouen, G.; Amatore, C. Ferrocene-Mediated Proton-Coupled Electron Transfer in a Series of Ferrocifen-Type Breast-Cancer Drug Candidates. Angewandte Chemie International Edition 2006, 45 (2), 285-290. https://doi.org/10.1002/anie.200502925.

(17) Messina, P.; Labbé, E.; Buriez, O.; Hillard, E. A.; Vessières, A.; Hamels, D.; Top, S.; Jaouen, G.; Frapart, Y. M.; Mansuy, D.; et al. Deciphering the Activation Sequence of Ferrociphenol Anticancer Drug Candidates. Chemistry - A European Journal 2012, 18 (21), 6581-6587. https://doi.org/10.1002/chem.201103378.

(18) Wang, Y.; Pigeon, P.; Top, S.; McGlinchey, M. J.; Jaouen, G. Organometallic Antitumor Compounds: Ferrocifens as Precursors to Quinone Methides. Angewandte Chemie International Edition 2015, $54 \quad$ (35), $10230-10233$. https://doi.org/10.1002/anie.201503048.

(19) Jaouen, G.; Pigeon, P.; Top, S. Metallocene Derivatives with Anticancer Activity, May 7, 2015.

(20) Gao, H.; Zhang, Q.; Yang, Y.; Jiang, X.; He, Q. Tumor Homing Cell Penetrating Peptide Decorated Nanoparticles Used for Enhancing Tumor Targeting Delivery and Therapy. International Journal of Pharmaceutics 2015, 478 (1), 240-250. https://doi.org/10.1016/j.ijpharm.2014.11.029.

(21) Yang, W.; Xia, Y.; Fang, Y.; Meng, F.; Zhang, J.; Cheng, R.; Deng, C.; Zhong, Z. Selective Cell Penetrating Peptide-Functionalized Polymersomes Mediate Efficient and Targeted Delivery of Methotrexate Disodium to Human Lung Cancer In Vivo. Advanced Healthcare Materials 2018, 7 (7), 1701135. https://doi.org/10.1002/adhm.201701135.

(22) Kondo, E.; Saito, K.; Tashiro, Y.; Kamide, K.; Uno, S.; Furuya, T.; Mashita, M.; Nakajima, K.; Tsumuraya, T.; Kobayashi, N.; et al. Tumour Lineage-Homing CellPenetrating Peptides as Anticancer Molecular Delivery Systems. Nat Commun 2012, 3, 951. https://doi.org/10.1038/ncomms1952.

(23) Futaki, S.; Nakase, I.; Tadokoro, A.; Takeuchi, T.; Jones, A. T. Arginine-Rich Peptides and Their Internalization Mechanisms. Biochemical Society Transactions 2007, 35 (4), 784-787. https://doi.org/10.1042/BST0350784.

(24) Mitchell, D. J.; Steinman, L.; Kim, D. T.; Fathman, C. G.; Rothbard, J. B. Polyarginine Enters Cells More Efficiently than Other Polycationic Homopolymers. The Journal of Peptide Research 2000, 56 (5), 318-325. https://doi.org/10.1034/j.13993011.2000.00723.x.

(25) Gioria, S.; Caputo, F.; Urbán, P.; Maguire, C. M.; Bremer-Hoffmann, S.; Prina-Mello, A.; Calzolai, L.; Mehn, D. Are Existing Standard Methods Suitable for the Evaluation of Nanomedicines: Some Case Studies. Nanomedicine 2018, 13 (5), 539-554. https://doi.org/10.2217/nnm-2017-0338.

(26) Halamoda-Kenzaoui, B.; Holzwarth, U.; Roebben, G.; Bogni, A.; Bremer-Hoffmann, S. Mapping of the Available Standards against the Regulatory Needs for Nanomedicines. Wiley Interdisciplinary Reviews: Nanomedicine and Nanobiotechnology 2019, 11 (1), e1531. https://doi.org/10.1002/wnan.1531.

(27) Caputo, F.; Clogston, J.; Calzolai, L.; Rösslein, M.; Prina-Mello, A. Measuring Particle Size Distribution of Nanoparticle Enabled Medicinal Products, the Joint View of EUNCL 
and NCI-NCL. A Step by Step Approach Combining Orthogonal Measurements with Increasing Complexity. $J$ Control Release 2019, 299, 31-43. https://doi.org/10.1016/j.jconrel.2019.02.030.

(28) Carpino, L. A.; Han, G. Y. 9-Fluorenylmethoxycarbonyl Function, a New Base-Sensitive Amino-Protecting Group. J. Am. Chem. Soc. 1970, 92 (19), 5748-5749. https://doi.org/10.1021/ja00722a043.

(29) Pedersen, S. L.; Tofteng, A. P.; Malik, L.; Jensen, K. J. Microwave Heating in Solid-Phase Peptide Synthesis. Chem. Soc. Rev. 2012, 41 (5), 1826-1844. https://doi.org/10.1039/C1CS15214A.

(30) Glushko, V.; Thaler, M. S. R.; Karp, C. D. Pyrene Fluorescence Fine Structure as a Polarity Probe of Hydrophobic Regions: Behavior in Model Solvents. Archives of Biochemistry and Biophysics 1981, 210 (1), 33-42. https://doi.org/10.1016/00039861(81)90160-0.

(31) Mandal, D.; Shirazi, A. N.; Parang, K. Self-Assembly of Peptides to Nanostructures. Org Biomol Chem 2014, 12 (22), 3544-3561. https://doi.org/10.1039/c4ob00447g.

(32) Mallamace, D.; Fazio, E.; Mallamace, F.; Corsaro, C. The Role of Hydrogen Bonding in the Folding/Unfolding Process of Hydrated Lysozyme: A Review of Recent NMR and FTIR Results. International Journal of Molecular Sciences 2018, 19 (12), 3825. https://doi.org/10.3390/ijms19123825.

(33) Smith, A. M.; Williams, R. J.; Tang, C.; Coppo, P.; Collins, R. F.; Turner, M. L.; Saiani, A.; Ulijn, R. V. Fmoc-Diphenylalanine Self Assembles to a Hydrogel via a Novel Architecture Based on $\pi-\pi$ Interlocked $\beta$-Sheets. Advanced Materials 2008, 20 (1), 37-41. https://doi.org/10.1002/adma.200701221.

(34) Huang, C.-W.; Mohamed, M. G.; Zhu, C.-Y.; Kuo, S.-W. Functional Supramolecular Polypeptides Involving $\pi-\pi$ Stacking and Strong Hydrogen-Bonding Interactions: A Conformation Study toward Carbon Nanotubes (CNTs) Dispersion. Macromolecules 2016, 49 (15), 5374-5385. https://doi.org/10.1021/acs.macromol.6b01060.

(35) Panahi, Y.; Farshbaf, M.; Mohammadhosseini, M.; Mirahadi, M.; Khalilov, R.; Saghfi, S.; Akbarzadeh, A. Recent Advances on Liposomal Nanoparticles: Synthesis, Characterization and Biomedical Applications. Artif Cells Nanomed Biotechnol 2017, 45 (4), 788-799. https://doi.org/10.1080/21691401.2017.1282496.

(36) Koppel, D. E. Analysis of Macromolecular Polydispersity in Intensity Correlation Spectroscopy: The Method of Cumulants. J. Chem. Phys. 1972, 57 (11), 4814-4820. https://doi.org/10.1063/1.1678153.

(37) Xu, C.; Wang, P.; Zhang, J.; Tian, H.; Park, K.; Chen, X. Pulmonary Codelivery of Doxorubicin and SiRNA by PH-Sensitive Nanoparticles for Therapy of Metastatic Lung Cancer. Small 2015, 11 (34), 4321-4333. https://doi.org/10.1002/smll.201501034.

(38) Kratky, O. X-Ray Small Angle Scattering with Substances of Biological Interest in Diluted Solutions. Progress in Biophysics and Molecular Biology 1963, 13, 105-IN1. https://doi.org/10.1016/S0079-6107(63)80015-2.

(39) Jakeš, J. Regularized Positive Exponential Sum (REPES) Program - A Way of Inverting Laplace Transform Data Obtained by Dynamic Light Scattering. Collect. Czech. Chem. Commun. 1995, 60 (11), 1781-1797. https://doi.org/10.1135/cccc19951781.

(40) Brown, W. Dynamic Light Scattering: The Method and Some Applications; Clarendon Press ; Oxford University Press: Oxford [England]; New York, 1993. 
(41) Eiríksdóttir, E.; Konate, K.; Langel, Ü.; Divita, G.; Deshayes, S. Secondary Structure of Cell-Penetrating Peptides Controls Membrane Interaction and Insertion. Biochimica et Biophysica Acta (BBA) - Biomembranes 2010, 1798 (6), 1119-1128. https://doi.org/10.1016/j.bbamem.2010.03.005.

(42) Gross, J.; Sayle, S.; Karow, A. R.; Bakowsky, U.; Garidel, P. Nanoparticle Tracking Analysis of Particle Size and Concentration Detection in Suspensions of Polymer and Protein Samples: Influence of Experimental and Data Evaluation Parameters. European Journal of Pharmaceutics and Biopharmaceutics 2016, 104, 30-41. https://doi.org/10.1016/j.ejpb.2016.04.013.

(43) Glatter, O. Chapter 2 - General Theorems and Special Cases. In Scattering Methods and their Application in Colloid and Interface Science; Glatter, O., Ed.; Elsevier, 2018; pp 1932. https://doi.org/10.1016/B978-0-12-813580-8.00002-X.

(44) Franconi, F.; Lemaire, L.; Siegler, B.; Gimel, J.-C.; Saulnier, P. NMR Diffusometry Data Sampling Optimization for Mixture Analysis. Journal of Pharmaceutical and Biomedical Analysis 2018, 148, 156-162. https://doi.org/10.1016/j.jpba.2017.09.028.

(45) D'Mello, S. R.; Cruz, C. N.; Chen, M.-L.; Kapoor, M.; Lee, S. L.; Tyner, K. M. The Evolving Landscape of Drug Products Containing Nanomaterials in the United States. Nature Nanotechnology 2017, 12 (6), 523-529. https://doi.org/10.1038/nnano.2017.67.

(46) Leong, H. S.; Butler, K. S.; Brinker, C. J.; Azzawi, M.; Conlan, S.; Dufés, C.; Owen, A.; Rannard, S.; Scott, C.; Chen, C.; et al. On the Issue of Transparency and Reproducibility in Nanomedicine. Nat. Nanotechnol. 2019, 14 (7), 629-635. https://doi.org/10.1038/s41565-019-0496-9.

(47) Mehn, D.; Caputo, F.; Rösslein, M.; Calzolai, L.; Saint-Antonin, F.; Courant, T.; Wick, P.; Gilliland, D. Larger or More? Nanoparticle Characterisation Methods for Recognition of Dimers. RSC Adv. 2017, 7 (44), 27747-27754. https://doi.org/10.1039/C7RA02432K.

(48) Varenne, F.; Makky, A.; Gaucher-Delmas, M.; Violleau, F.; Vauthier, C. Multimodal Dispersion of Nanoparticles: A Comprehensive Evaluation of Size Distribution with 9 Size Measurement Methods. Pharm Res 2016, 33 (5), 1220-1234. https://doi.org/10.1007/s11095-016-1867-7.

(49) Maguire, C. M.; Rösslein, M.; Wick, P.; Prina-Mello, A. Characterisation of Particles in Solution - a Perspective on Light Scattering and Comparative Technologies. Science and Technology of Advanced Materials 2018, 19 (1), 732-745. https://doi.org/10.1080/14686996.2018.1517587. 


\section{Supporting information}

Supplementary Figure S1: Chemical structure and synthesis of the ferrocifen p54

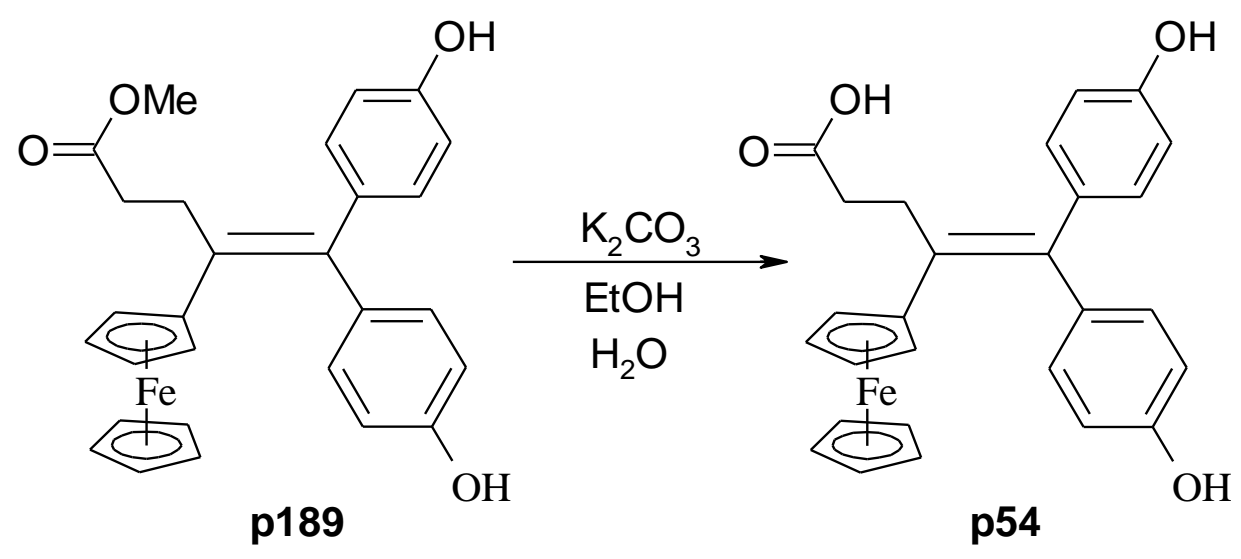

\section{Materials}

Rink amid p-methylbenzhydrylamine (MBHA) resin $(0.69 \mathrm{mmol} / \mathrm{g})$ were purchased from Multisyntech GmbH (Germany). Dimethylformamide (DMF), methyl alcohol (MeOH), trifluoroacetic acid (TFA), thioanisole, triisopropyl silane (TIS) and acetonitrile (ACN) were purchased from Thermo Fisher Scientific (USA). All amino acids derivatives, piperidine, 2-(1Hbenzotriazol-1-yl)-1,1,3,3-tetramethyluronium hexafluorophosphate (HBTU) and diisopropylethylamine (DIEA) were purchased from Iris Biotech GmbH (Germany). Phenol was collected from Merck KGaA (Germany). Diethyl ether, LC-MS grade water and ULC/MS grade ACN were purchased from Biosolve (France). Deionized water was obtained from a Milli-Q plus system (Merck-Millipore, Germany). Formic acid, potassium carbonate, acetone and pyrene were obtained from Sigma-Aldrich (France). Ethyl acetate, petroleum ether, ethanol and hydrochloric acid were obtained from VWR (France).

\section{Supplementary Section S1: Synthesis of p54, CPP and CPP-p54 conjugates.}

4-Ene-4-ferrocenyl-5,5-bis-(4-hydroxyphenyl)-pentanoic acid, p54. A mixture of ester p189 (0.464 g, $0.962 \mathrm{mmol})$, potassium carbonate $(0.532 \mathrm{~g}, 3.8 \mathrm{mmol})$, water $(10 \mathrm{~mL})$ and ethanol (35 $\mathrm{mL}$ ) was refluxed for 6 hours. After cooling, water and ethyl acetate were added and the mixture was shacked with acidification by slow addition of concentrated hydrochloric acid. The mixture was then decanted. The aqueous layer was extracted with ethyl acetate and the combination of organic layers was dried on magnesium sulfate, filtered then concentrated under reduced pressure. The crude solid was dissolved into ethyl acetate and was cooled to $-30{ }^{\circ} \mathrm{C}$ after addition of petroleum ether. The crystallized p54 $(0.43 \mathrm{~g}$, yield $96 \%)$ was recovered by filtration and dried under reduced pressure. ${ }^{1} \mathrm{H}$ NMR $\left(300 \mathrm{MHz}\right.$, acetone- $\left.\mathrm{d}_{6}\right): \delta 2.46\left(\mathrm{t}, J=8.2 \mathrm{~Hz}, 2 \mathrm{H}, \mathrm{CH}_{2}\right)$, $2.97\left(\mathrm{t}, J=8.2 \mathrm{~Hz}, 2 \mathrm{H}, \mathrm{CH}_{2}\right), 3.03(\mathrm{~s}$ broad, $1 \mathrm{H}, \mathrm{OH}), 4.00\left(\mathrm{t}, J=1.9 \mathrm{~Hz}, 2 \mathrm{H}, \mathrm{C}_{5} \mathrm{H}_{4}\right), 4.13(\mathrm{t}, J=$ $\left.1.9 \mathrm{~Hz}, 2 \mathrm{H}, \mathrm{C}_{5} \mathrm{H}_{4}\right), 4.18(\mathrm{~s}, 5 \mathrm{H}, \mathrm{Cp}), 6.74\left(\mathrm{~d}, J=8.7 \mathrm{~Hz}, 2 \mathrm{H}, \mathrm{C}_{6} \mathrm{H}_{4}\right), 6.86(\mathrm{~d}, J=8.7 \mathrm{~Hz}, 2 \mathrm{H}$, $\left.\mathrm{C}_{6} \mathrm{H}_{4}\right), 6.91\left(\mathrm{~d}, J=8.7 \mathrm{~Hz}, 2 \mathrm{H}, \mathrm{C}_{6} \mathrm{H}_{4}\right), 7.12\left(\mathrm{~d}, J=8.7 \mathrm{~Hz}, 2 \mathrm{H}, \mathrm{C}_{6} \mathrm{H}_{4}\right), 8.30(\mathrm{~s}, 1 \mathrm{H}, \mathrm{OH}), 8.35(\mathrm{~s}$, $1 \mathrm{H}, \mathrm{OH}) .{ }^{13} \mathrm{C}$ NMR $(75 \mathrm{MHz}$, acetone-d 6$): \delta 31.7\left(\mathrm{CH}_{2}\right), 35.8\left(\mathrm{CH}_{2}\right), 69.6\left(2 \mathrm{CH} \mathrm{C}_{5} \mathrm{H}_{4}\right), 70.6$ $(5 \mathrm{CH} \mathrm{Cp}), 70.7\left(2 \mathrm{CH} \mathrm{C}_{5} \mathrm{H}_{4}\right), 88.9\left(\mathrm{C} \mathrm{C}_{5} \mathrm{H}_{4}\right), 116.5\left(2 \mathrm{CH} \mathrm{C}_{6} \mathrm{H}_{4}\right), 116.8\left(2 \mathrm{CH} \mathrm{C}_{6} \mathrm{H}_{4}\right), 131.9(2 \mathrm{CH}$ 
$\left.\mathrm{C}_{6} \mathrm{H}_{4}\right), 132.5\left(2 \mathrm{CH} \mathrm{C}_{6} \mathrm{H}_{4}\right), 134.4(\mathrm{C}), 137.4(\mathrm{C}), 137.9$ (C), 140.9 (C), 157.6 (2C), $175.1(\mathrm{CO})$. MS (CI, NH $)_{3}$ m/z: $469[\mathrm{M}+\mathrm{H}]^{+}, 485\left[\mathrm{M}+\mathrm{NH}_{4}\right]^{+}$.

CPPs were synthesized on a Rink Amide MBHA resin $(0.69 \mathrm{mmol} / \mathrm{g})$ via a standard Fmoc solid phase peptide synthesis (SPPS) method, with an automated microwave peptide synthesizer (CEM). First, the resin was immersed in DMF and gently stirred to swell the resin beads for $2 \mathrm{~h}$ at room temperature. The first step is the Fmoc deprotection using $20 \%$ piperidine/DMF (v/v). Then, the resin was washed several times with DMF. Subsequently, the amino acid coupling reaction was done by adding a DMF-mixed solution of Fmoc-protecting amino acid (5 equiv.), HBTU (4.5 equiv.), and DIEA (10 equiv.). These steps were performed using a microwave assisted system and cycles of deprotection-washing-coupling-washing were repeated until the desired amino-acid sequence was obtained. After this step, we can either keep the peptide free or conjugate the ferrocifen molecule to the N-terminal extremity of the peptide. For thus, after the final Fmoc deprotection with piperidine/DMF, the ferrocifen (2 equiv.) was solubilized in DMF in presence of HBTU (2 equiv.). In order to activate the carboxylic acid function, the solution was stirred for $5 \mathrm{~min}$ before adding DIEA (3 equiv.). The coupling mixture was immediately added to the resin beads and the coupling reaction was performed for $2 \mathrm{~h}$ at $37^{\circ} \mathrm{C}$. Finally, the resin was washed with $\mathrm{DMF}$ and $\mathrm{MeOH}$ three times, respectively, and dried under vacuum for $48 \mathrm{~h}$. Peptides and conjugates were cleaved from the resin by adding the appropriate cleavage cocktail based on the amino acid sequence. For polyarginine, reagent $\mathrm{K}$ was used (mixture of TFA, phenol, water, thioanisole and TIS in the volume ratio of 82.5:5:5:5:2.5) and reagent $\mathrm{B}$ (mixture of TFA, phenol, water and TIS in the volume ratio of 88:5:5:2) was used for RLW. After adding the cleavage cocktail ( $5 \mathrm{~mL}$ of solution for $0.5 \mathrm{~g}$ of resin), the resin was stirred at $37^{\circ} \mathrm{C}$ during $1-4 \mathrm{~h}$. The crude peptide was precipitated by adding the cleavage mixture dropwise to at least a 10-fold excess of cold diethyl ether: the resulting precipitate was centrifuged for 30 $\min$ at $4^{\circ} \mathrm{C}$ at $2000 \mathrm{rpm}$. Afterward, the crude product was dissolved in water/ACN before freeze-drying.

\section{Supplementary Section S2: Purification and characterization of CPP and CPP-p54 conjugates.}

The crude products were purified by semi-preparative reversed phase high-performance liquid chromatography (RP-HPLC) using a Waters (France) instrument. Purification was performed at room temperature using XBridge BEH C18 Prep column $(250 \times 30 \mathrm{~mm})$ with $5 \mu \mathrm{m}$ particle and $130 \AA$ A pore size. Eluent (A) was $0.1 \%$ TFA in water while eluent (B) contained $0.1 \% \mathrm{TFA}$ in ACN. A gradient elution was developed for both RLW based products and $\operatorname{Arg}_{\mathrm{n}}$ based products (peptides and conjugates) (Table 1). The crude product was dissolved in $95 \%$ (A) and $5 \%$ (B) at a concentration of $4 \mathrm{mg} / \mathrm{mL}$. The sample was vortexed, sonicated and filtered with a $0.22 \mu \mathrm{m}$ Millex-LG filter (Merck, Germany). Flow rate was $44 \mathrm{~mL} / \mathrm{min}$ and injection volume was 2.5 $\mathrm{mL}$. Peaks were detected at a wavelength of $214 \mathrm{~nm}$ for peptides (amide bond) and $450 \mathrm{~nm}$ for conjugates (ferrocifen part). 
Table 4 Gradient elution of the RP-HPLC method

\begin{tabular}{|l|l|l|l|}
\hline Time (minutes) & Flow (mL/minute) & Phase A (\%) & Phase B (\%) \\
\hline 0 & 44 & 95 & 5 \\
\hline 12 & 44 & 80 & 20 \\
\hline 45 & 44 & 70 & 30 \\
\hline 47 & 44 & 0 & 100 \\
\hline 57 & 44 & 0 & 100 \\
\hline 59 & 44 & 95 & 5 \\
\hline 75 & 44 & 95 & 5 \\
\hline
\end{tabular}

Notes: Phase (A) contained 0.1\% TFA in water and phase (B) $0.1 \%$ TFA in ACN

The LC-MS/MS method was developed on an Alliance ${ }^{\circledR} 2695$ system (Waters) with a $150 \times 2.0$ $\mathrm{mm}, 5 \mu \mathrm{m}$ Uptisphere C18 5ODB column (Interchim, France). The mobile phase consisted of a mixture of (A) $0.1 \%$ formic acid in water and (B) $0.1 \%$ formic acid in ACN. The gradient elution used was adapted function of the peptide used (Tables 2 and 3). The purified product was dissolved in $95 \%$ (A) and $5 \%$ (B) at a concentration of $1 \mathrm{mg} / \mathrm{mL}$. The sample was vortexed, sonicated and filtered with a $0.22 \mu \mathrm{m}$ Millex-LG filter (Merck, Germany). Flow rate was 0.2 $\mathrm{mL} / \mathrm{min}$ and the injection volume was set at $5 \mu \mathrm{L}$. The total HPLC effluent was injected into a Quattro Micro®triple quadrupole mass spectrometer (Waters, France). Ionization was achieved using electrospray in positive ion mode in the $\mathrm{m} / \mathrm{z} 200-1500$ range (full scan acquisition). An option of cone ramp was used between 20 and $60 \mathrm{~V}$ to optimize the acquisition.

Table 5 Gradient elution of the LC-MS/MS method for RLW based products

\begin{tabular}{|l|l|l|l|}
\hline Time (minutes) & Flow (mL/minute) & Phase A (\%) & Phase B (\%) \\
\hline 0 & 0.3 & 0 & 100 \\
\hline 5 & 0.3 & 0 & 100 \\
\hline
\end{tabular}


Table 6 Gradient elution of the LC-MS/MS method for $\operatorname{Arg}_{n}$ based products

\begin{tabular}{|l|l|l|l|}
\hline Time (minutes) & Flow (mL/minute) & Phase A (\%) & Phase B (\%) \\
\hline 0 & 0.2 & 50 & 50 \\
\hline 8 & 0.2 & 50 & 50 \\
\hline 9 & 0.2 & 0 & 100 \\
\hline 12 & 0.2 & 0 & 100 \\
\hline 13 & 0.2 & 50 & 50 \\
\hline 15 & 0.2 & 50 & 50 \\
\hline
\end{tabular}

Notes: Phase (A) contained $0.1 \%$ formic acid in water and phase (B) $0.1 \%$ formic acid in ACN

An UPLC-UV method was developed to quantify the purity of peptides and conjugates. An UPLC Acquity H-Class Bio (Waters, France) composed of a quaternary solvent manager, a sample manager, a photo diode array detector and a column manager was used. The system was managed by Empower ${ }^{\circledR} 3$ software (Waters). The column used was an Acquity®UPLC BEH C18 $100 \times 2.1 \mathrm{~mm}, 1.7 \mu \mathrm{m}$ (Waters). The mobile phase was composed of a mixture of $0.1 \%$ TFA in water (A) and $0.1 \%$ TFA in ACN. The purified product was dissolved in $95 \%$ (A) and 5 $\%$ (B) at a concentration of $1 \mathrm{mg} / \mathrm{mL}$. The sample was vortexed, sonicated and filtered with a $0.22 \mu \mathrm{m}$ Millex-LG filter (Merck-Millipore, Germany). Flow rate was $0.2 \mathrm{~mL} / \mathrm{min}$ and injection volume was set to $1 \mu \mathrm{L}$. The gradient elution changed with the peptide used (Tables 4 and 5). Detection was fixed at $214 \mathrm{~nm}$ and $450 \mathrm{~nm}$.

Table 7 Gradient elution of the UPLC-UV method for RLW based products

\begin{tabular}{|l|l|l|l|}
\hline Time (minutes) & Flow (mL/minute) & Phase A (\%) & Phase B (\%) \\
\hline 0 & 0.2 & 80 & 20 \\
\hline 10 & 0.2 & 0 & 100 \\
\hline 11 & 0.2 & 80 & 20 \\
\hline 18 & 0.2 & 80 & 20 \\
\hline
\end{tabular}

Notes: Phase (A) contained 0.1\% TFA in water and phase (B) $0.1 \%$ TFA in ACN 
Table 8 Gradient elution of the UPLC-UV method for $\operatorname{Arg}_{n}$ based products

\begin{tabular}{|l|l|l|l|}
\hline Time (minutes) & Flow (mL/minute) & Phase A (\%) & Phase B (\%) \\
\hline 0 & 0.2 & 95 & 5 \\
\hline 5 & 0.2 & 78 & 22 \\
\hline 10 & 0.2 & 78 & 22 \\
\hline 15 & 0.2 & 0 & 100 \\
\hline 20 & 0.2 & 0 & 100 \\
\hline 21 & 0.2 & 95 & 5 \\
\hline 25 & 0.2 & 95 & 5 \\
\hline
\end{tabular}

Notes: Phase (A) contained $0.1 \%$ TFA in water and phase (B) $0.1 \%$ TFA in ACN

Nuclear magnetic resonance (NMR) spectroscopy.

${ }^{1} \mathrm{H}$ NMR spectra were recorded in deuterated dimethyl sulfoxide and deuterated water at 250 $\mathrm{MHz}$ or $400 \mathrm{MHz}$ in the FT mode with a Bruker $500 \mathrm{MHz}$ AVANCE III HD spectrometer (Wissembourg, France) equilibrated at $25{ }^{\circ} \mathrm{C}$. Spectra were analyzed using the software MestReNova ${ }^{\circledR}$. 
Supplementary Figure S2: Chromatograms and ${ }^{1} \mathrm{H}$ NMR spectra obtained for CPP and CPP-p54 by LC-MS/MS. (A) $\operatorname{Arg}_{6}$, (B) $\operatorname{Arg}_{7}$, (C) $\operatorname{Arg}_{8}$, (D) $\operatorname{Arg}_{9}$, (E) RLW, (F) $\operatorname{Arg}_{6}$-p54, (G) $\operatorname{Arg}_{7}-\mathrm{p54}$, (H) $\mathrm{Arg}_{8}-\mathrm{p54}$, (I) $\operatorname{Arg}_{9}$-p54, (J) RLW-p54.

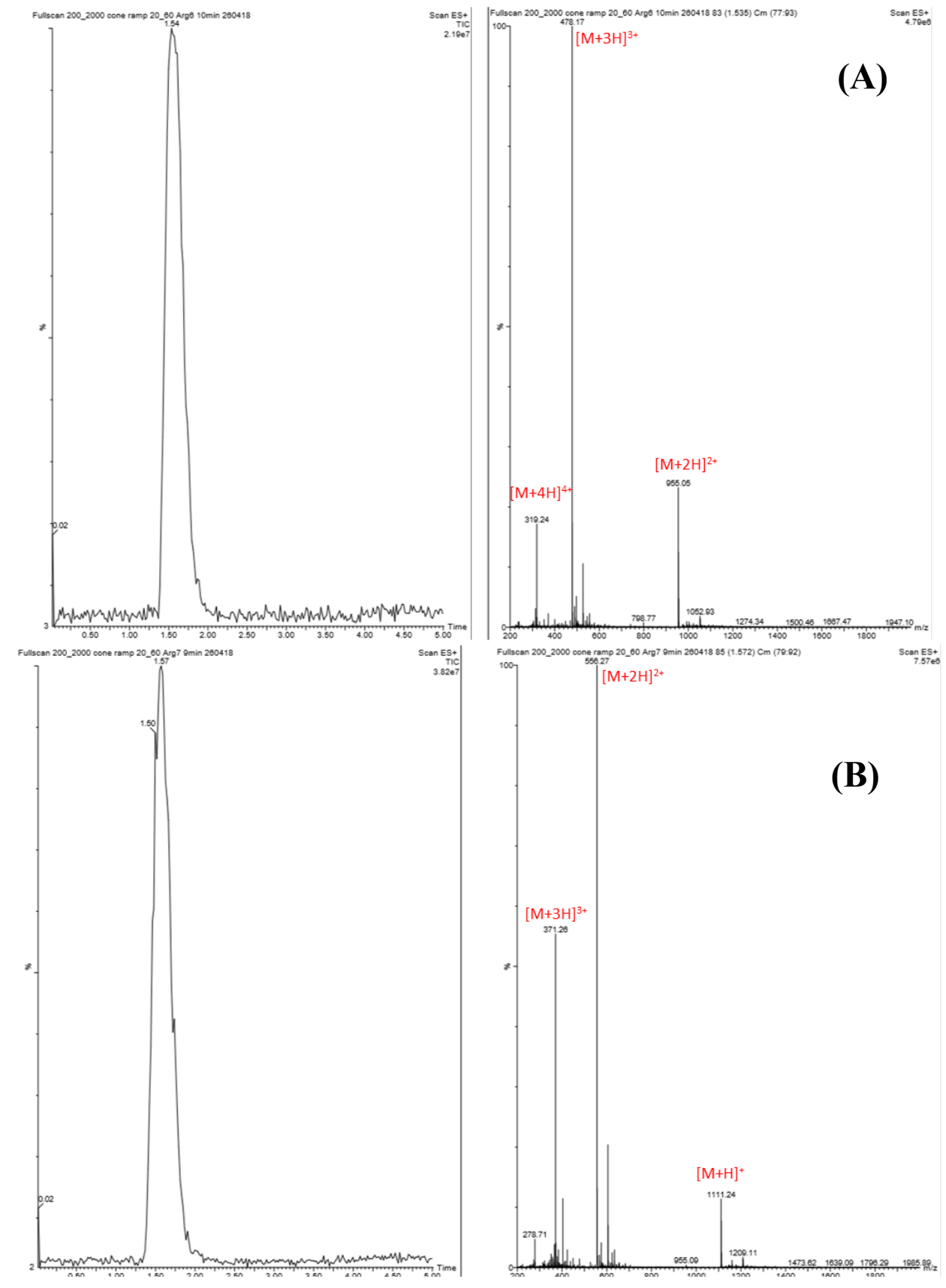




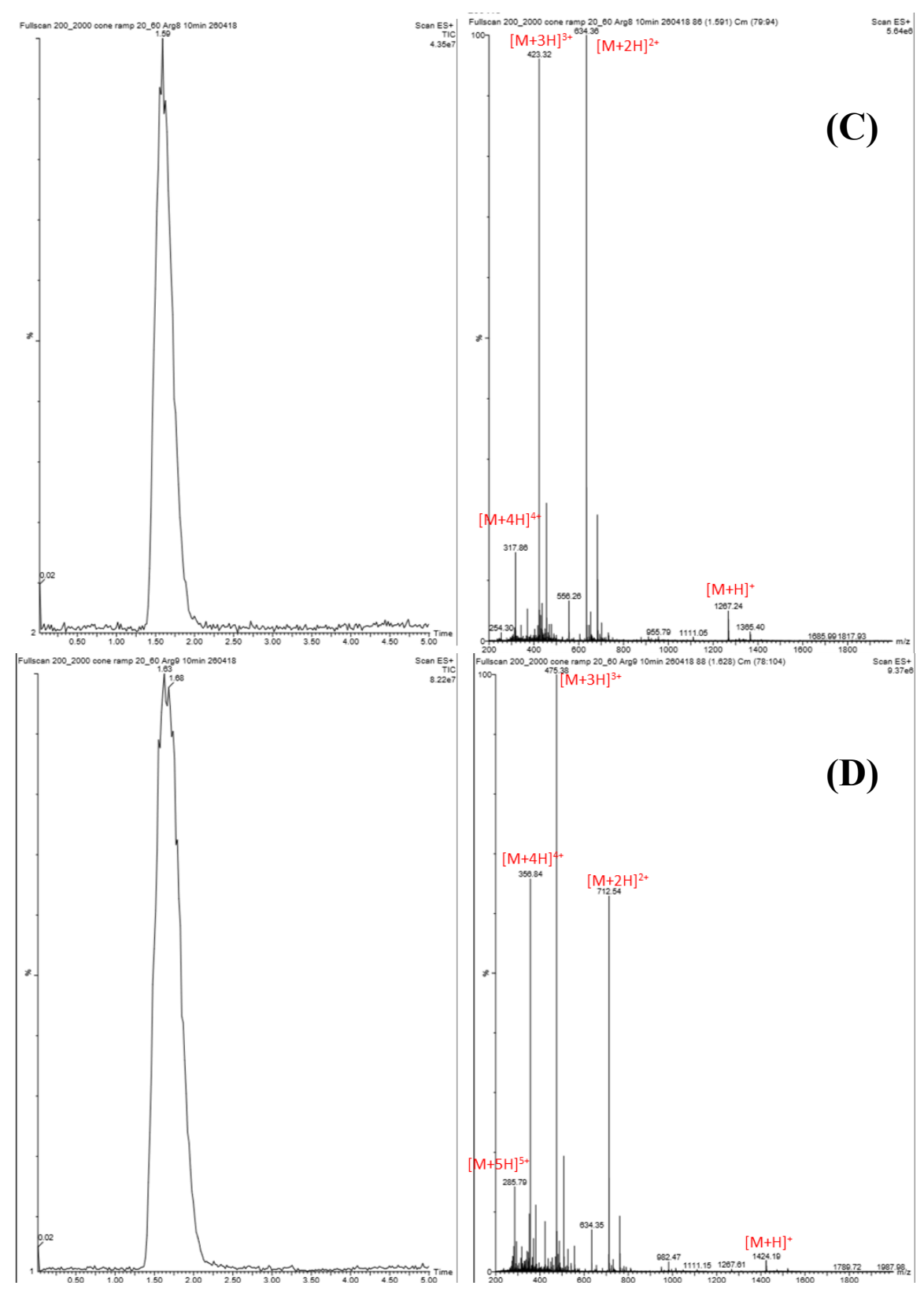




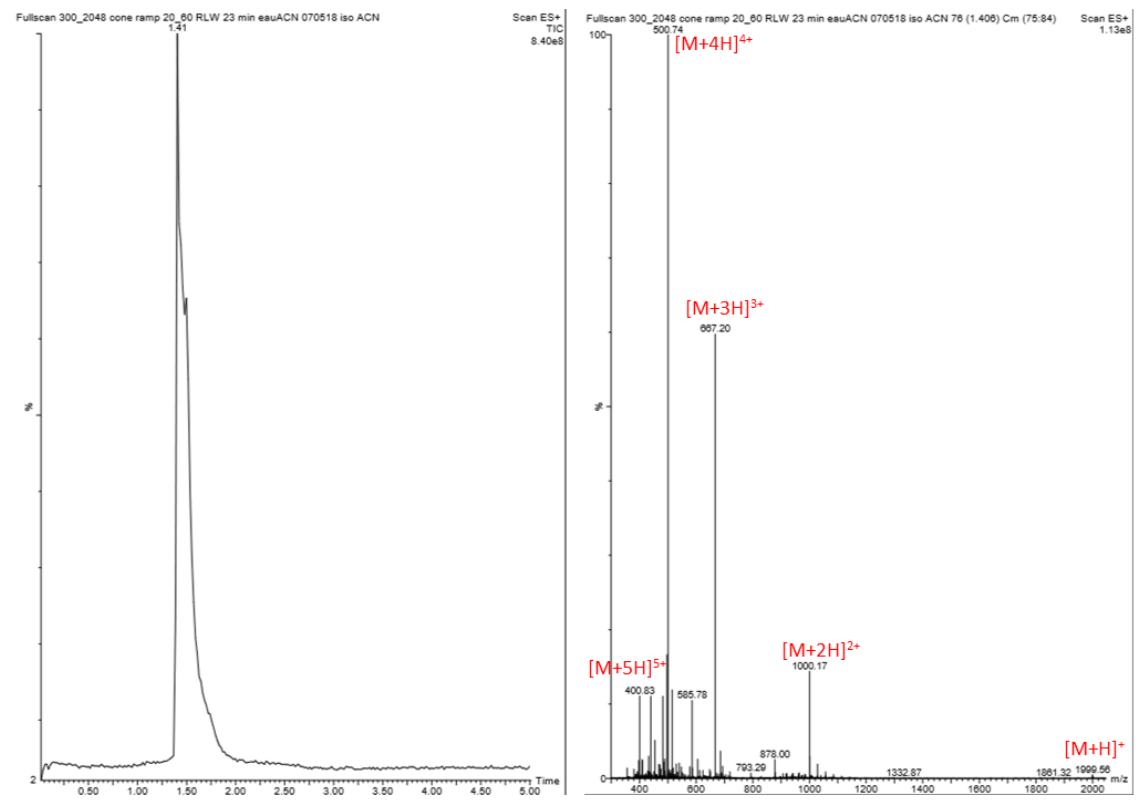

(E) 


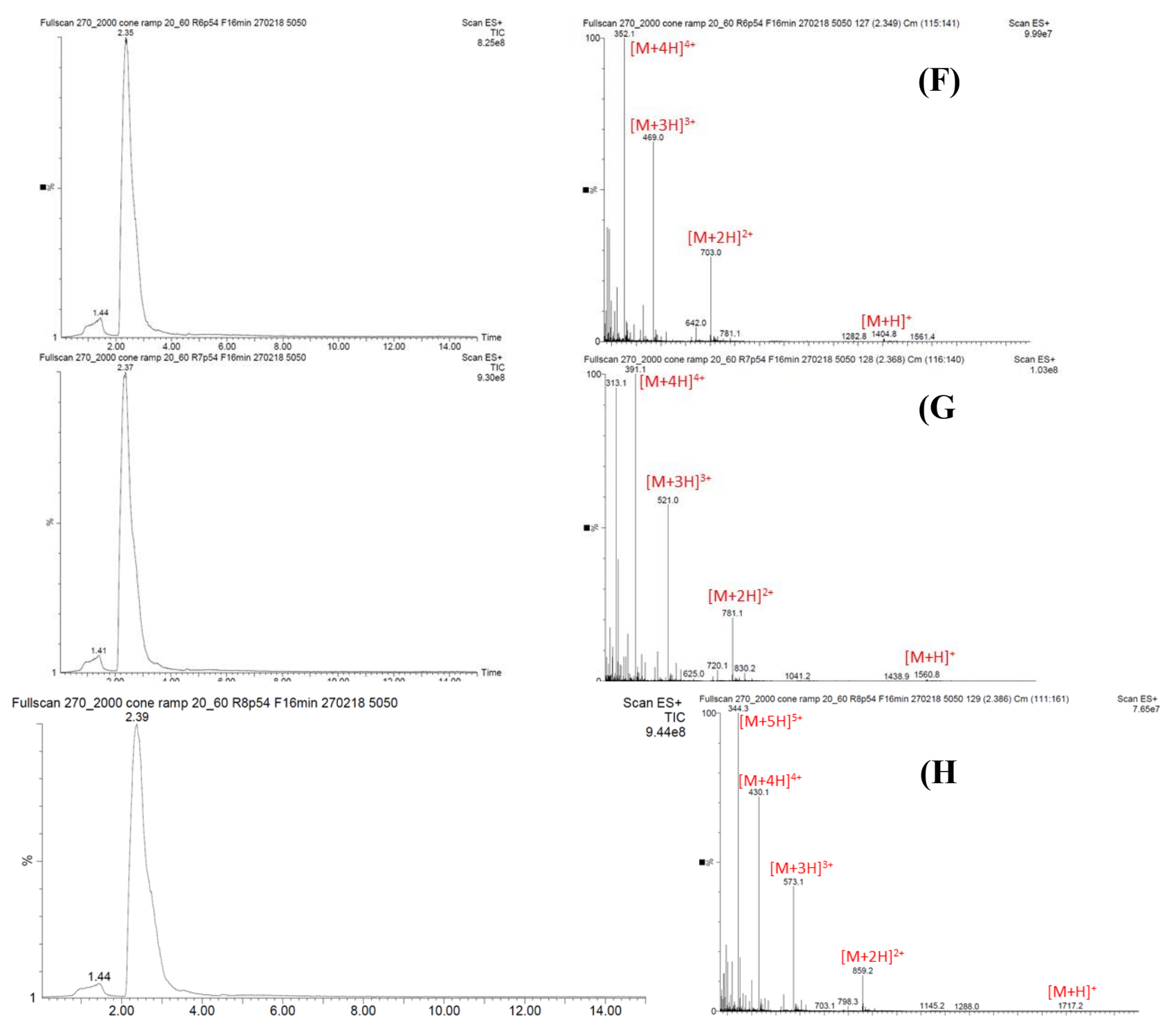



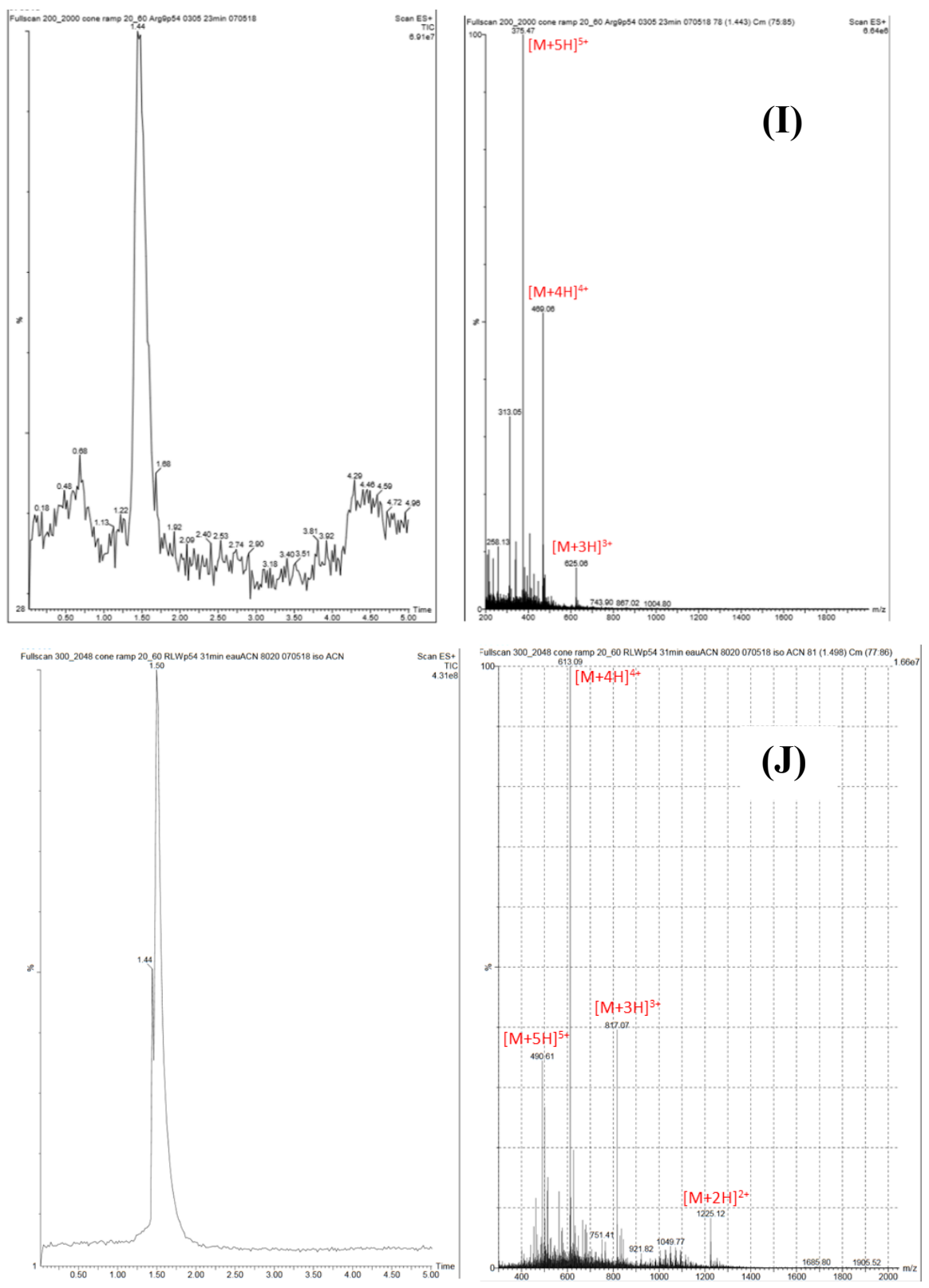

\begin{tabular}{|c|c|c|c|c|c|c|c|c|c|c|}
\hline & \multicolumn{5}{|c|}{$\mathrm{CPP}$} & \multicolumn{5}{|c|}{ CPP-p54 conjugates } \\
\hline & $\operatorname{Arg}_{6}$ & $\operatorname{Arg}_{7}$ & $\operatorname{Arg}_{8}$ & $\operatorname{Arg}_{9}$ & RLW & $\begin{array}{c}\operatorname{Arg}_{6^{-}} \\
\text {p54 }\end{array}$ & $\begin{array}{c}\operatorname{Arg}_{7-} \\
\text { p54 }\end{array}$ & $\begin{array}{c}\mathrm{Arg}_{8}- \\
\text { p54 }\end{array}$ & $\begin{array}{c}\operatorname{Arg}_{9^{-}} \\
\text {p54 }\end{array}$ & $\begin{array}{c}\text { RLW- } \\
\text { p54 }\end{array}$ \\
\hline Yield & $55 \%$ & $64 \%$ & $70 \%$ & $78 \%$ & $19 \%$ & $20 \%$ & $21 \%$ & $23 \%$ & $24 \%$ & $23 \%$ \\
\hline Purity & $97 \%$ & $97 \%$ & $89 \%$ & $85 \%$ & $99 \%$ & $88 \%$ & $89 \%$ & $98 \%$ & $94 \%$ & $88 \%$ \\
\hline
\end{tabular}

Supplementary Table S1: Yield and purity of CPP and CPP-p54 obtained. 


\section{Supplementary Section S3: determination of critical aggregation concentration (CAC).}

The critical aggregation concentration (CAC) of CPP-p54 suspensions was determined using pyrene as a fluorescent probe. Briefly, $6 \mu \mathrm{L}$ of pyrene stock solution in acetone $(50 \mu \mathrm{M})$ was added into tubes. Then, acetone in tubes was evaporated in dark condition. Different suspension of CPP-p54 with a concentration ranging from 0.5 to $1500 \mu \mathrm{M}$ were added into tubes and mixed overnight at $37^{\circ} \mathrm{C}$. The final concentration of pyrene was $1 \mu \mathrm{M}$. After 30 min of equilibration at room temperature. A fluorescence spectrophotometer (Fluoromax-4, Horiba, Japan) was used to measure the fluorescence intensities of pyrene at an excitation wavelength of $336 \mathrm{~nm}$. The emission spectra were recorded in the range $350-500 \mathrm{~nm}$. The slit opening for the excitation was set at $1 \mathrm{~nm}$ and $3 \mathrm{~nm}$ for the emission. Intensity ratios of pyrene at $I_{372} / I_{382}\left(I_{1} / I_{3}\right)$ were plotted against the log of the concentration.

\section{Supplementary Figure S3: Quotient of vibrational band intensities $\left(I_{1} / I_{3}\right)$ as a function of $\log [$ [CPP-p54] and $\log [\mathrm{p5} 5]$.}
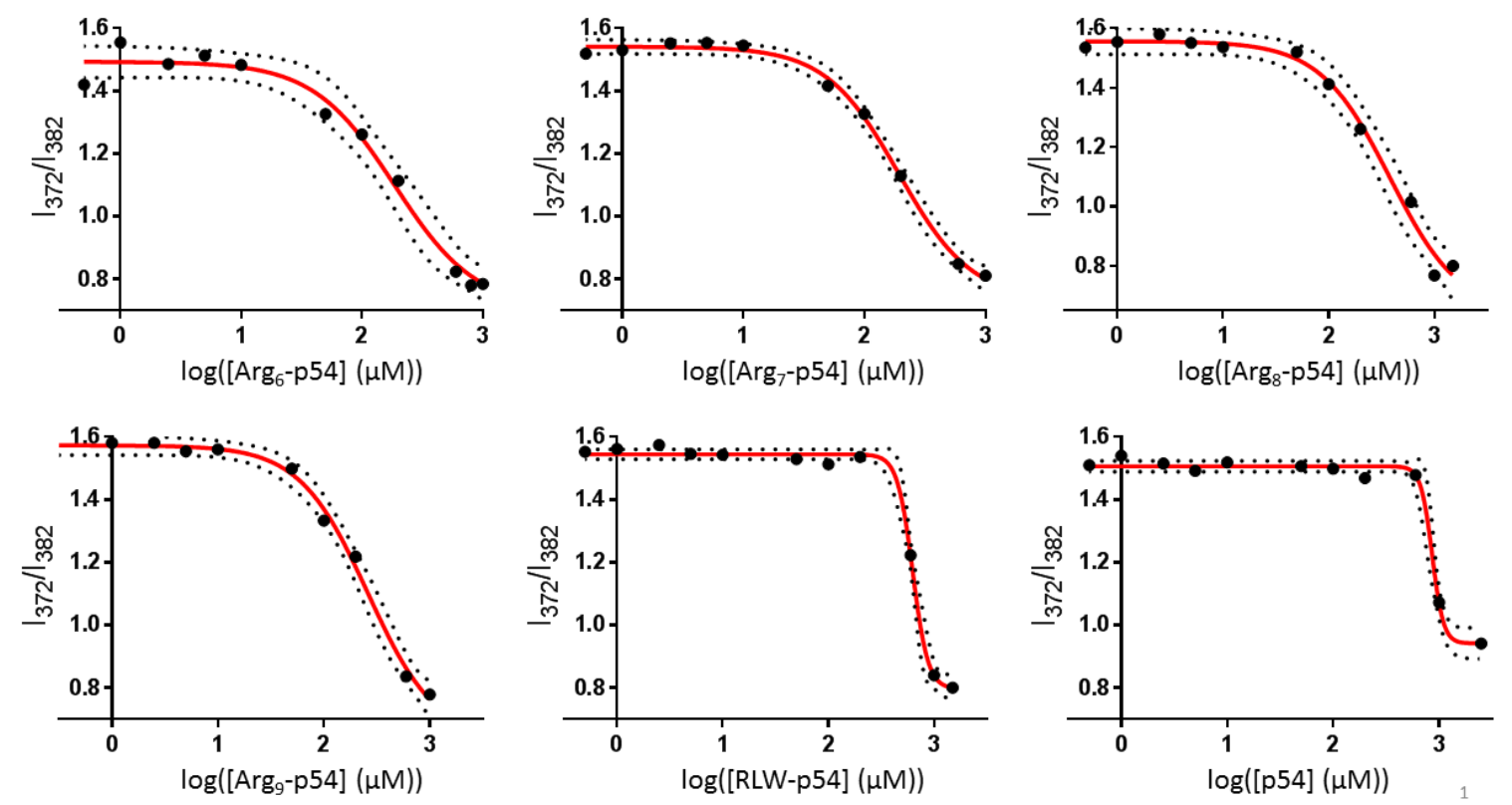
Supplementary Figure S4: Quotient of vibrational band intensities $\left(I_{1} / I_{3}\right)$ as a function of $\log [\mathrm{CPP}]$.
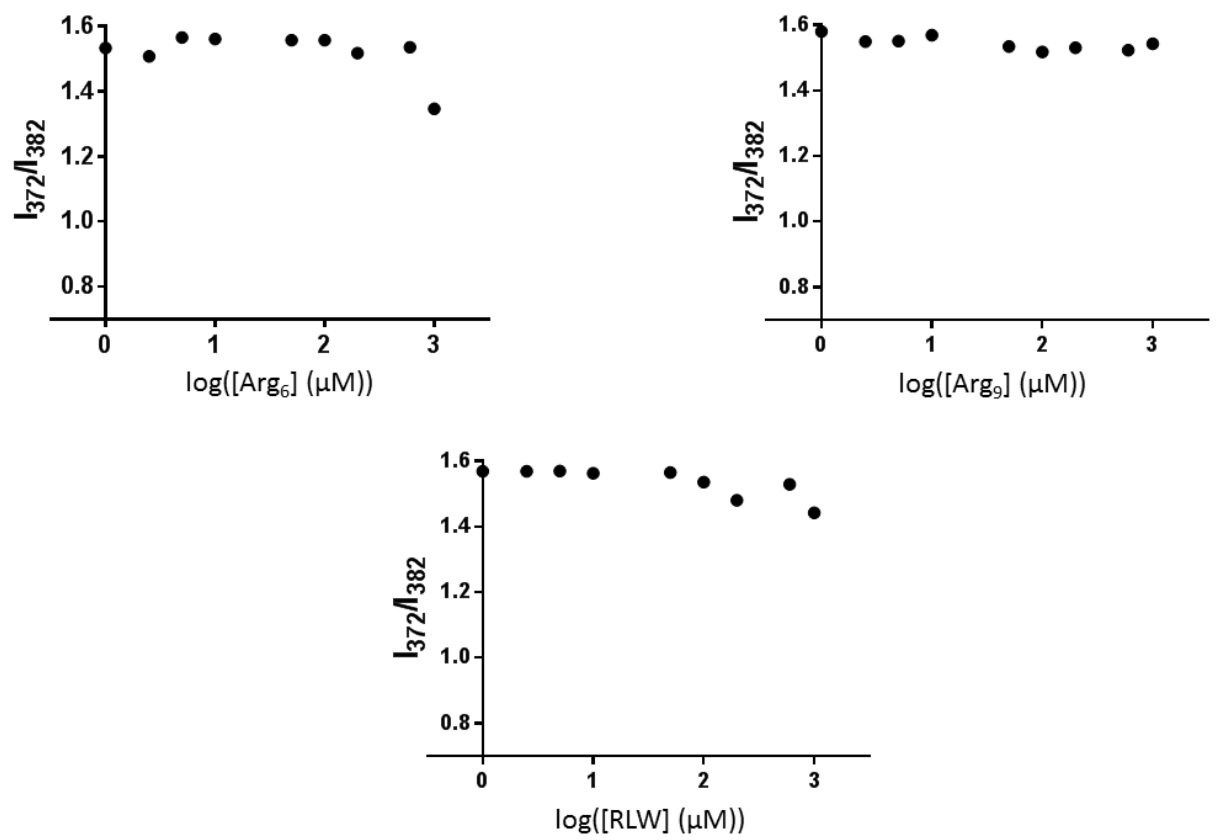

Supplementary Figure S5: Stability study of CPP-p54 self-assemblies. Stability was assessed by measuring the hydrodynamic diameter $(\mathrm{nm})$ by DLS $(\mathrm{n}=3)$.

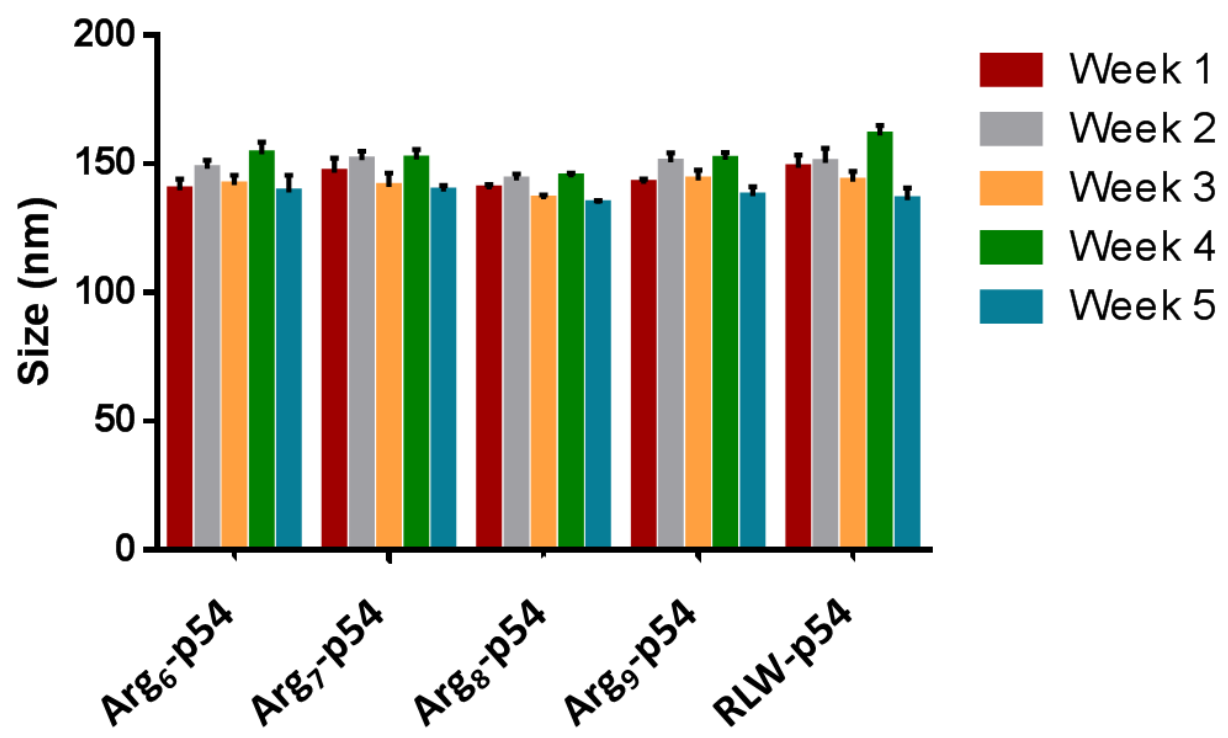




\section{Supplementary Section S4: Self-assembly formulations process.}

Nanoassemblies were formulated by nanoprecipitation using a solvent displacement technique. For thus, conjugates ( $\operatorname{Arg}_{\mathrm{n}}-\mathrm{p} 54$ and RLW-p54) were solubilized in acetone at a concentration of $2.55 \mathrm{mg} / \mathrm{mL}$. This organic solution was added in a microfluidic mixer (IDEX U-466-02, USA) at a flow rate of $300 \mu \mathrm{L} / \mathrm{min}$ with a syringe pump (Harvard Apparatus PHD 2000 infusion, USA). In the same time, water was added at a flow rate of $1200 \mu \mathrm{L} / \mathrm{min}$ with a second syringe pump (Harvard Apparatus PHD Ultra, USA). In fact, the individual flow rates of each channel were selected to have an acetone/water volume ratio of 4 for all experiments. The organic solvent was then removed using a rotary evaporator, and the final concentration obtained was of $0.85 \mathrm{mg} / \mathrm{mL}$.

Supplementary Figure S6: DLS measurement in water at $20^{\circ} \mathrm{C}$ of a $200 \mathrm{~nm}$ filtered $\operatorname{Arg}_{6}-$ p54 suspension. Evolution of the average relaxation rate, $\Gamma$, as a function of the square scattering vector, $q^{2} \cdot \Gamma$ was calculated using the cumulant method. The red line corresponds to a linear fit. Its slope gives the $z$ average diffusion coefficient $D=5.19 \pm \mathbf{0 . 0 3}$ $\mu \mathrm{m}^{2} / \mathrm{s}$ corresponding to a hydrodynamic diameter $\mathrm{d}_{\mathrm{H}}=86.2 \pm 0.5 \mathrm{~nm} .1 .002 \mathrm{mPa} \cdot \mathrm{s}$ was used for the water viscosity at $20^{\circ} \mathrm{C}$.

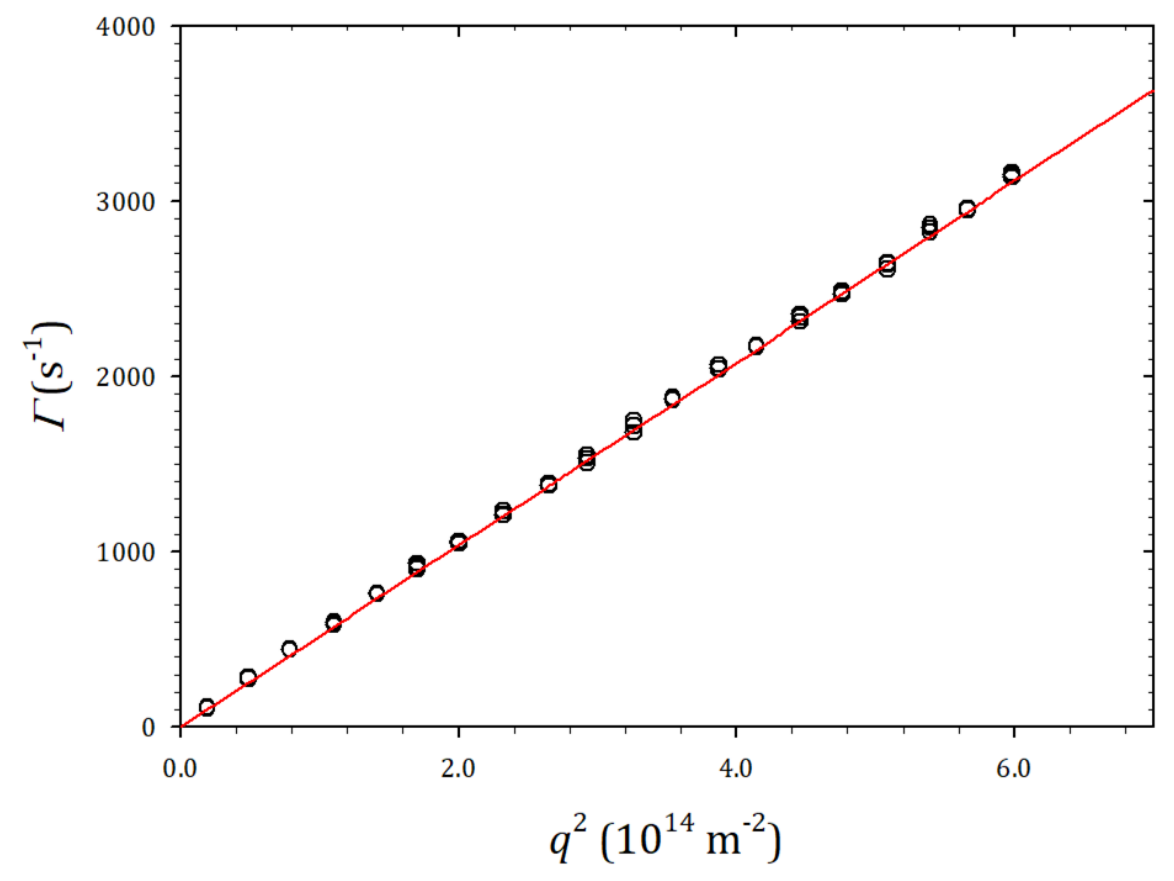

Supplementary Section S5: Dynamic light scattering. 
The autocorrelation function of the scattering intensity, $g_{2}(t)$ is related to the autocorrelation function of the electric field, $g_{1}(t)$, by the Siegert relation: $g_{2}(t)=1+\beta \cdot g_{1}(t)^{2}$ where $\beta$ is called the intercept. This intercept is usually close to unity but can be low for weakly scattering samples.

$\mathrm{g}_{1}(\mathrm{t})$ can be written as the Laplace transform of a relaxation time distribution $\mathrm{A}(\tau)$ : $\mathrm{g}_{1}(\mathrm{t})=\int \mathrm{A}(\tau) \cdot \exp (-\mathrm{t} / \tau) \cdot \mathrm{d} \tau$

For suspensions of diluted rigid particles, each relaxation time is related to a diffusion coefficient $\mathrm{D}=1 /\left(\tau \cdot \mathrm{q}^{2}\right)$. Using the Stokes-Einstein relation, an intensity weighted hydrodynamic size distribution can be obtained. The shape of this distribution can be influenced by the form factor, when particles are big compared to the $\mathrm{q}^{-1}{ }^{1}$

\section{Supplementary Section S6: Cryogenic Transmission Electron Microscopy (Cryo-TEM).}

Cryogenic Transmission Electron Microscopy (Cryo-TEM) investigations were performed with a Cryo-TEM (Tecnai ${ }^{\mathrm{TM}}$ G2 Sphera, FEI, USA), at the Microscopy Rennes Imaging Center (Biogenouest, Rennes). A drop $(4 \mu \mathrm{L})$ of the $(10 \mathrm{mg} / \mathrm{mL})$ sample was deposited on the surface of a carbon-coated copper grid. This gird was held under controlled humidity and temperature conditions by tweezers on a guillotine device. A filter paper was then pressed against the sample to remove the excess liquid. Afterward, the filter paper is removed, and the plunger was allowed to drop into the liquid ethane in order to vitrify the sample. The gird was then transferred to a cryo-holder. Observations were made at an accelerating voltage of $200 \mathrm{kV}$ under low electron dose. Analysis was performed with the ImageJ software.

\section{Supplementary Section S7: Nanoparticle Tracking Analysis (NTA).}

The NTA was carried out using the NanoSight NS300 (Malvern Instruments Ltd, UK). For thus, the suspensions were diluted in ultrapure water in order to have optimum concentration ranging between $1 \times 10^{8}$ and $1 \times 10^{9}$ particles per $\mathrm{mL}$ to allow analysis of the software to track the movement of particle. Prior to each analysis, samples were filtered using a $0.20 \mu \mathrm{m}$ Whatman ${ }^{\mathrm{TM}}$ Anotop $^{\mathrm{TM}}$ filter. Ultrapure water and suspensions were infused in the sample chamber using a syringe pump at $80 \mu \mathrm{L} / \mathrm{min}$ rate. A $405 \mathrm{~nm}$ laser was used to illuminate the particles, and their Brownian motion was recorded into $60 \mathrm{~s}$ videos (25 fps) using the sCMOS type camera of the instrument. Subsequently, the NTA software (NTA 3.2 Dev Build 3.2.16) allowed for processing of the data. The nanoparticle concentration was obtained after correction by the dilution factor. The experiment was performed in triplicate. 
Supplementary Figure S7: Concentration (particles/mL) function of the size of self-

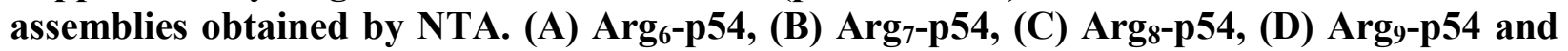
(E) RLW-p54.
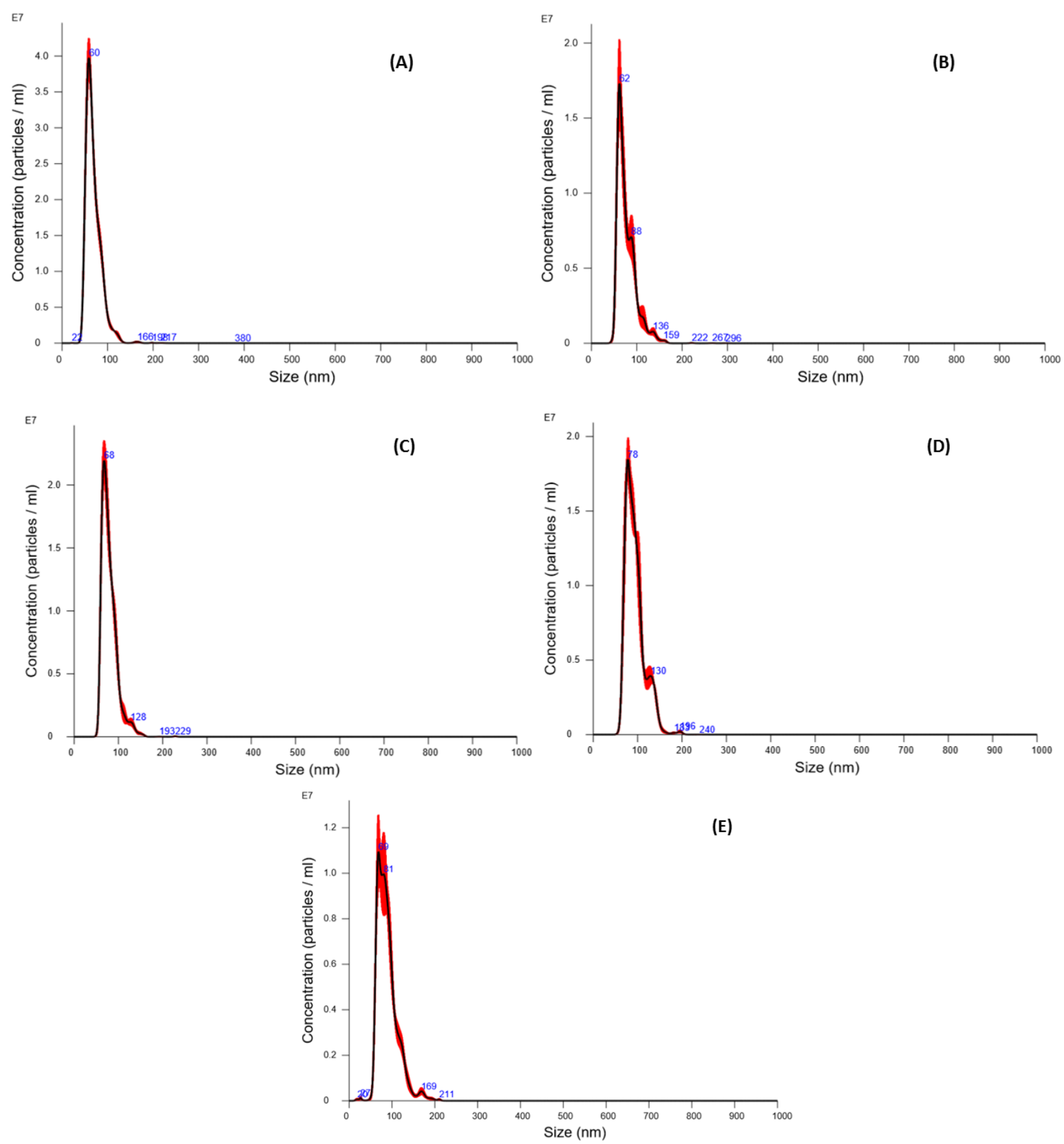

Supplementary Section S8: Small-angle X-ray scattering (SAXS).

SAXS experiments were conducted on the SWING beamline at the SOLEIL synchrotron (Saint Aubin, France). The Aviex charge-coupled device detector was positioned at a distance of $1.8 \mathrm{~m}$. 
Data were collected as a function of the scattering vector $q=\frac{4 \pi \sin \theta}{\lambda}$, where $2 \theta$ is the scattering angle and $\lambda$ the wavelength of the incident beam. Silver behenate standard was used to calibrate the range. Samples were injected via an automated sample changer into a quartz capillary (1.5 mm internal diameter, $10 \mu \mathrm{m}$ wall thickness). Suspensions were streamed at a constant flow rate through the capillary during beam exposure to avoid possible degradation under X-ray irradiation. The SAXS beamline was operated at $11 \mathrm{keV}$. Data were collected by a two-dimensional CCD detector. Intensity values were normalized taking into account the beam intensity, acquisition time and sample transmission. The scattered intensity from a capillary filled with water was subtracted from the sample scattering curves. The analysis of the SAXS data was carried out using the FOXTROT software.

Supplementary Table S2: Features of CPP-p54 self-assemblies obtained by SAXS experiments: number fraction, mass fraction, intensity fraction, gyration radius, hydrodynamic radius obtained by the inverse Laplace transformation, hydrodynamic radius obtained by the method of cumulants and polydispersity index. These results were determined assuming that homogeneous sphere with the same electron density were obtained.

\begin{tabular}{|c|c|c|c|c|c|c|c|c|c|}
\hline & \multicolumn{2}{|c|}{$\operatorname{Arg}_{6}-\mathrm{p} 54$} & \multicolumn{2}{|c|}{$\operatorname{Arg}_{7}-\mathrm{p} 54$} & \multicolumn{2}{|c|}{$\operatorname{Arg}_{8}-\mathrm{p} 54$} & \multicolumn{2}{|c|}{$\mathrm{Arg}_{9}-\mathrm{p} 54$} & \multirow{2}{*}{$\begin{array}{c}\text { RLW-p54 } \\
\text { D1 }\end{array}$} \\
\hline & D2 & D1 & D2 & D1 & D2 & D1 & D2 & D1 & \\
\hline Number fraction & 1.000 & 0.000 & 1.000 & 0.000 & 1.000 & 0.000 & 1.000 & 0.000 & 1.000 \\
\hline Mass fraction & 0.871 & 0.129 & 0.929 & 0.071 & 0.939 & 0.061 & 0.949 & 0.051 & 1.000 \\
\hline Intensity fraction & 0.003 & 0.997 & 0.001 & 0.999 & 0.002 & 0.998 & 0.006 & 0.994 & 1.000 \\
\hline$\sqrt{\left\langle\boldsymbol{R}_{\boldsymbol{g}}^{2}\right\rangle_{\mathrm{z}}}(\mathrm{nm})$ & 1.1 & 16.2 & 1.8 & 23.0 & 1.5 & 25.3 & 1.5 & 14.8 & 4.7 \\
\hline$\left\langle\boldsymbol{R}_{\boldsymbol{h}}\right\rangle_{\boldsymbol{z}}(\mathrm{nm})$ & 1.3 & 18.9 & 1.9 & 25.5 & 1.6 & 27.6 & 1.6 & 17.7 & 5.4 \\
\hline$\left\langle R_{h}^{-1}\right\rangle_{z}^{-1}(n m)$ & 1.1 & 15.6 & 1.3 & 18.7 & 1.1 & 19.4 & 1.2 & 15.1 & 4.1 \\
\hline Pdl & 0.198 & 0.217 & 0.523 & 0.216 & 0.472 & 0.428 & 0.368 & 0.173 & 0.317 \\
\hline
\end{tabular}

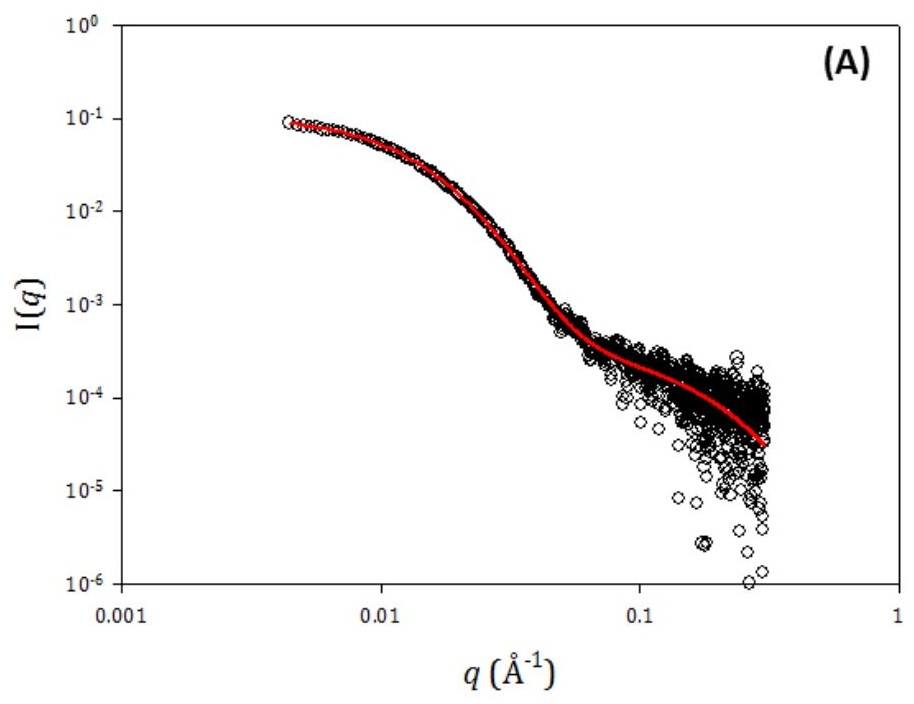

Supplementary Figure S8: Smallangle $\mathrm{X}$-ray scattering patterns recorded at room temperature and fitted curves obtained for (A) Arg $_{6-}^{-}$ p54, (B) $\operatorname{Arg}_{7}-p 54$, (C) $\operatorname{Arg}_{8}-p 54$, (D) Arg9-p54 and (E) RLW-p54. Open circles are experimental data and the full red line represents the fit to the data using two log-normal distributions of spheres. 

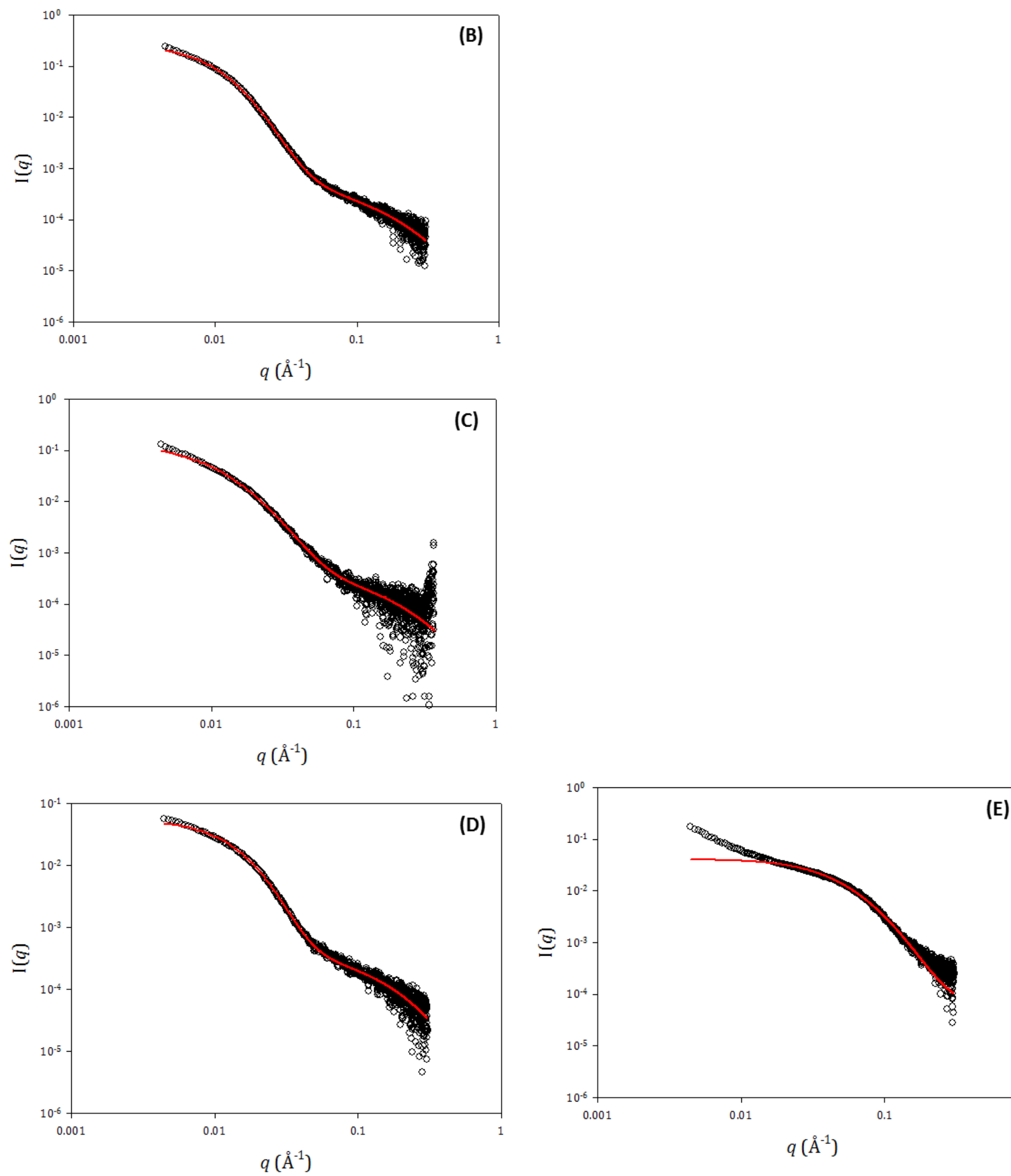


\section{Supplementary Section S9: NMR diffusometry.}

${ }^{1} \mathrm{H}$ NMR pulsed field gradient acquisition (PFG-NMR), also called diffusion ordered spectroscopy (DOSY), was performed on $\mathrm{Arg}_{6}-54$ self-assemblies $(9 \mathrm{mg} / \mathrm{mL})$ in deuterated water at $25{ }^{\circ} \mathrm{C}$ after a $0.2 \mu \mathrm{m}$ filtration. A Bruker $500 \mathrm{MHz}$ AVANCE III HD spectrometer (Wissembourg, France) equipped with a $5 \mathrm{~mm}$-BBFO probe at the ASTRAL NMR facility from Angers University was used. In DOSY measurements, diffusion coefficients are estimated related to chemical shift by the observation of the exponential decay of the NMR signal due to the self-diffusion behaviour taking place between the two gradients of magnetic field ${ }^{2}$.

In case of a mixture, the signal can be represented by the Laplace transform of a diffusion coefficient distribution, $f(D)$, of species that contribute to the signal: $S(b)=S 0 \cdot f(D) \cdot \exp (-$ $D \cdot b) \cdot d D$, where $b$ is called the diffusion weighted factor. $b$ is expressed as: $b=\gamma^{2} \cdot g^{2} \cdot \delta^{2} \cdot(\Delta-\delta / 3)$, with $\gamma$ the gyromagnetic ratio, $g$ the gradient intensity, $\delta$ the gradient duration and $\Delta$ the gradient separation.

Diffusion experiments were performed using the stimulated echo sequence with longitudinal Eddy current delay (LED), ledgp 2s. As the larger objects diffusivity was not possible to estimate due to their small contribution, the acquisition parameters were chosen to optimally evaluate diffusion coefficients of the smaller objects ${ }^{3}$. The diffusion time $\Delta$ was $200 \mathrm{~ms}$, the diffusion gradient duration $\delta$ was $2.4 \mathrm{~ms}$, the gradient shape ramp was linear with 128 steps and the number of averages was 96 . The gradient magnitude ranged from 5 to $95 \%$ of the maximum

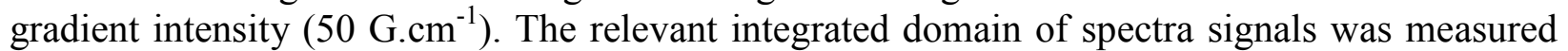
using TOPSPIN 3.6.1 (Bruker, Wissembourg), then analysed using the REPES ILT algorithm. Hydrodynamic diameters were calculated from the estimated diffusion coefficient $\mathrm{D}$ according to Stokes-Einstein relation (using $1.10 \mathrm{mPa} \cdot \mathrm{s}$ for $\mathrm{D}_{2} \mathrm{O}$ viscosity at $25{ }^{\circ} \mathrm{C}$ and $0.31 \mathrm{mPa} \cdot \mathrm{s}$ for deuterated acetone viscosity at $25^{\circ} \mathrm{C}$ ). 


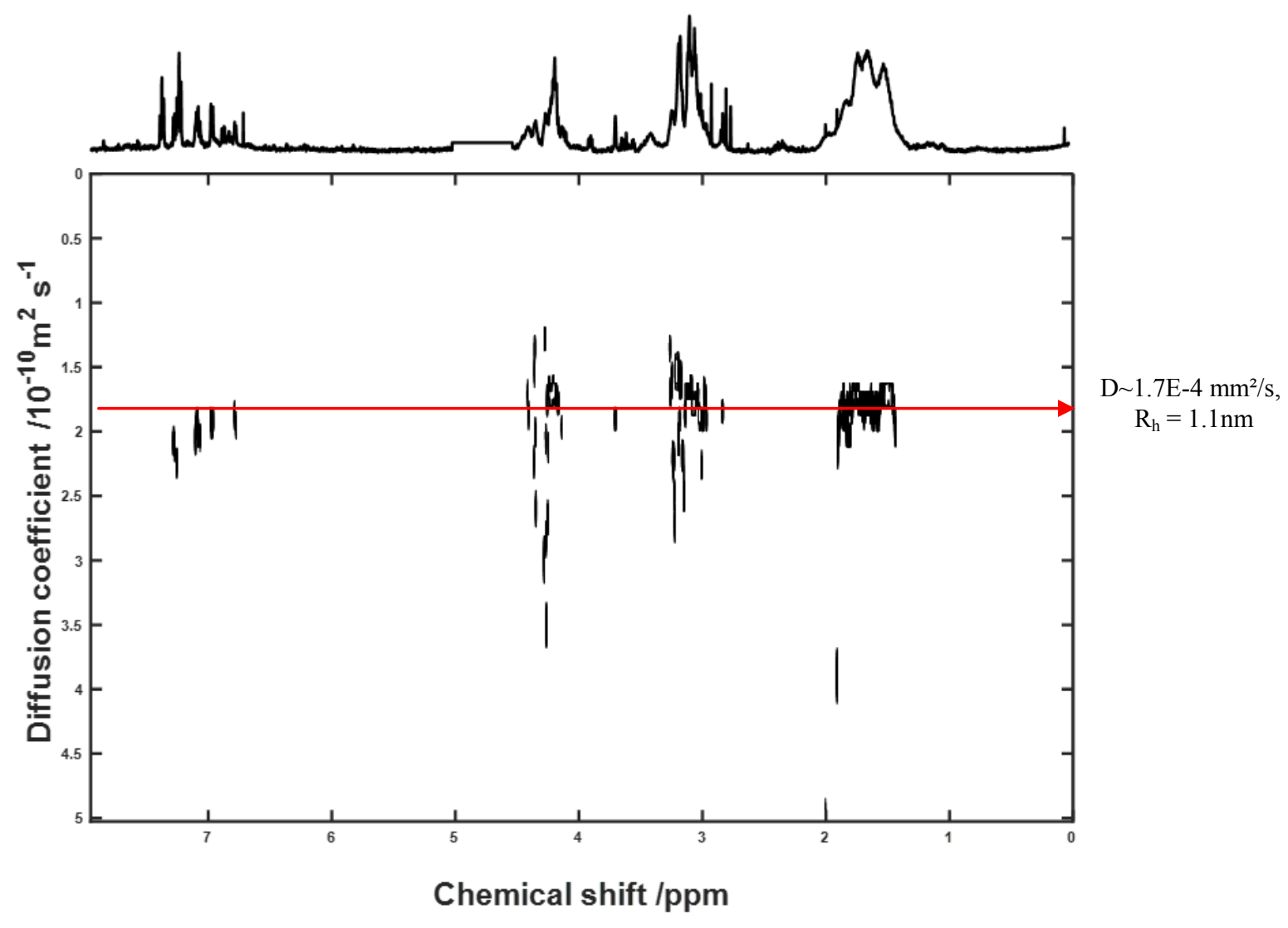


Supplementary Figure S9: Results obtained by NMR diffusometry in deuterated acetone: (a) ${ }^{1}$ H NMR spectra in deuterated acetone of p54 (red curve) and Arg $_{6}$-p54 (black curve). Dashed lines display integration domains used to characterize proton signals from p54 (Sp5: 7.149 - 6.580 ppm) and $\operatorname{Arg}_{6}\left(S_{\mathrm{R} 6}: 4.514\right.$ - $\left.4.198 \mathrm{ppm}\right)$. (b) DOSY experiments in deuterated acetone $25{ }^{\circ} \mathrm{C}$. Attenuation of integrated NMR signals as a function of the diffusion weighted factor, $b$, for p54 (circles) and $\operatorname{Arg}_{6}$ (triangles). Lines correspond to the fit of the experimental points, $\mathbf{p 5 4}$ (red) and $\mathrm{Arg}_{6}$ (blue) using the REPES ILT algorithm. (c) Corresponding diffusion coefficient distributions obtained from the ILT of signals displayed in figure S9 b, p54 (red) and $\mathrm{Arg}_{6}$ (blue). Average diffusion coefficients are 847 $\mu^{2} / \mathrm{s}$ (blue) and $890 \mu \mathrm{m}^{2} / \mathrm{s}$ (red). Both correspond to objects with a hydrodynamic diameter close to $1.6 \mathrm{~nm}$.

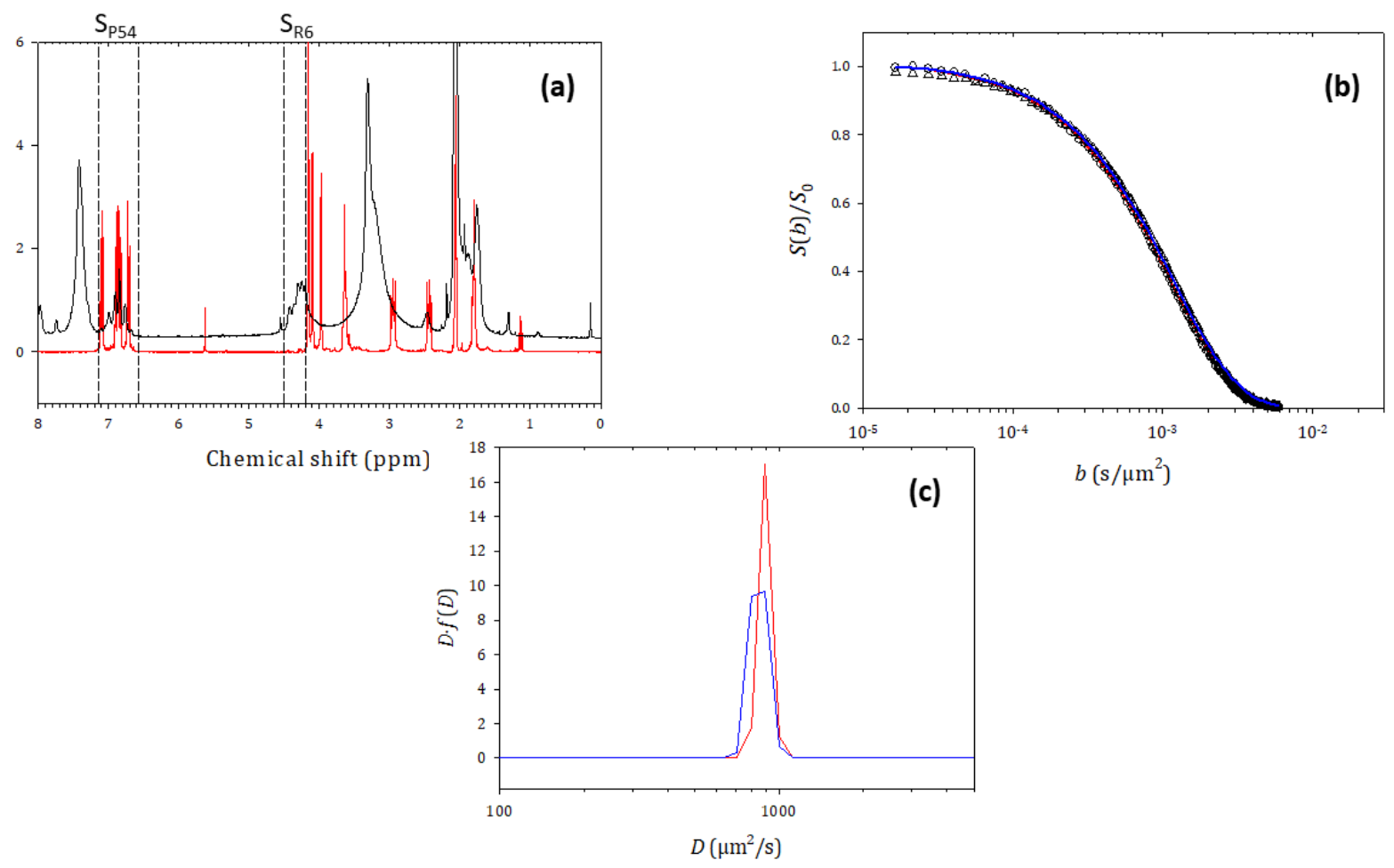




\section{REFERENCES}

(1) Glatter, O. Scattering Methods and Their Application in Colloid and Interface Science; 2018, Amsterdam: Elsevier.

(2) Stejskal, E. O.; Tanner, J. E. Spin Diffusion Measurements: Spin Echoes in the Presence of a Time-Dependent Field Gradient. J. Chem. Phys. 1965, 42 (1), 288-292. https://doi.org/10.1063/1.1695690.

(3) Franconi, F.; Lemaire, L.; Siegler, B.; Gimel, J.-C.; Saulnier, P. NMR Diffusometry Data Sampling Optimization for Mixture Analysis. J. Pharm. Biomed. Anal. 2018, 148, 156-162. https://doi.org/10.1016/j.jpba.2017.09.028. 